DOI: $10.1002 / \mathrm{smll} .201501350$

Article type: Concepts

\title{
Exploring Two-Dimensional Transport Phenomena in Metal Oxide Heterointerfaces for Next Generation High-Performance Thin-Film Transistor Technologies
}

John G. Labram ${ }^{\dagger}$, Yen-Hung Lin ${ }^{\dagger}$, Thomas D. Anthopoulos ${ }^{*}$

Dr. J. G. Labram, Mr. Y.-H. Lin, Prof. T. D. Anthopoulos

Department of Physics and Centre for Plastic Electronics

Blackett Laboratory

Imperial College London

London SW7 2BW, United Kingdom

*E-mail: thomas.anthopoulos@imperial.ac.uk

Keywords: energy quantization, metal oxides, semiconductors, transistors, heterostructures, two-dimensional transport, solution processing

Abstract: In the last decade metal oxides have emerged as a fascinating class of electronic materials, exhibiting a wide-range of unique and technologically relevant characteristics. For example, thin-film transistors formed from amorphous or poly-crystalline metal oxide semiconductors offer the promise of low-cost, large-area and flexible electronics, exhibiting performances comparable to or in excess of incumbent silicon-based technologies. Atomically flat interfaces between otherwise insulating or semiconducting complex oxides, are also found to be highly conducting, displaying 2-dimensional charge transport properties, strongcorrelations and even superconductivity. Field-effect devices employing such carefully engineered interfaces are hoped to one day compete with traditional group IV or III-V semiconductors for use in the next-generation of high-performance electronics. In this Concepts Article we provide an overview of the different metal oxide transistor technologies and potential future research directions. In particular we look at the recent reports of multilayer oxide thin-film transistors and the possibility of two-dimensional electron transport in these disordered/polycrystalline systems and discuss the potential of the technology for applications in large-area electronics. 


\section{Introduction}

The success of group IV and III-V semiconductors has undoubtedly been one of humankind's greatest achievements, ${ }^{[1]}$ with the rise of inexpensive consumer electronic devices revolutionizing almost every facet of Western society. Of particular relevance to this revolution has been the development of the so-called modulation-doped high electron mobility transistor (HEMT) technology. ${ }^{[2-4]}$ In these devices dopant impurities are kept spatially separate from the transistor channel, reducing the impact of scattering from impurity ions, subsequently resulting in staggering charge carrier transport properties. At the time of publication, peak charge carrier mobilities exceeding $30 \times 10^{6} \mathrm{~cm}^{2} \mathrm{~V}^{-1} \mathrm{~s}^{-1}$ have been reported, albeit at cryogenic temperatures. ${ }^{[5]}$

Recently, metal oxides have emerged as a class of materials that are attracting substantial attention, due to their broad range of unique properties. ${ }^{[6-9]}$ In particular, thin filmtransistors (TFTs) based on metal oxide semiconductors present academia and industry with the remarkable opportunity to create a new generation of low-cost, large-area electronics that are potentially compatible with inexpensive and temperature-sensitive flexible substrate materials. $^{[6-7]}$ Whilst the performance of these devices is already superior to incumbent technologies such as organic TFTs or amorphous silicon TFTs [Figure 1] ${ }^{[10]}$ the widespread commercialization of metal oxide TFTs demands further improvement of some of the main figures of merit, such as charge-carrier mobility, forcing device physicists and engineers to look for new and innovative solutions. Elsewhere, developments in epitaxial growth techniques over the last couple of decades ${ }^{[11-14]}$ have enabled the formation of oxide structures layer-by-layer, with atomically-flat terminating planes, opening the door to a wide range of novel phenomena, such as 2-dimensional charge transport, ${ }^{[15-17]}$ strongly-correlated carriers ${ }^{[8]}$ and high-temperature superconductivity. ${ }^{[18-20]}$ 
In this article we aim to summarize the field of oxide-based transistors and where future emphasis from the research community will likely be placed. An overview is provided of developments in strongly-correlated oxide-oxide interfaces and how highly-conducting 2dimensional electron gases (2DEGs) are formed at these interfaces. The current state-of-the art in this field is reviewed, describing how field-effect devices can be engineered from $\mathrm{SrTiO}_{3} / \mathrm{LaAlO}_{3}$ perovskite or $\mathrm{Mg}_{\mathrm{x}} \mathrm{Zn}_{1-\mathrm{x}} \mathrm{O} / \mathrm{ZnO}$ wurzite interfaces. The field of oxide TFTs is then introduced, in-which large-area low cost devices can be formed by employing amorphous or polycrystalline metal oxide semiconductors. Finally, TFT developments of the last few years are covered, where inspiration from traditional HEMTs and innovative strongly-correlated oxide-oxide systems has been applied to produce hetero-structured, multilayer metal oxide TFTs. The concepts of analogous modulation doped structures and quantized carrier states in disordered systems are discussed, and outlooks for the future are examined.

\section{Two-Dimensional Electron Gases at Oxide-Oxide Interfaces}

\subsection{Oxide Systems}

Due to their highly ionic nature, complex metal oxides possess a number of unique properties $^{[8-9,21-22]}$ offering physicists and material scientists access to a much broader region of parameter space than that offered by traditional semiconductor systems such as $\mathrm{Si}$, Ge or GaAs. Unfortunately, growth techniques for complex metal oxides have trailed those of group IV or III-V semiconductors, which have for several decades dominated the world of highperformance electronics. ${ }^{[3]}$ However, in the past 10-20 years dramatic developments in oxide molecular beam epitaxy $(\mathrm{MBE})^{[12-13]}$ and pulsed laser deposition (PLD) ${ }^{[11]}$ have led to the possibility of forming epitaxial oxide structures layer-by-layer, with well-defined and controlled terminating planes. ${ }^{[14-15]}$ Combined with the ability to monitor layer-by-layer growth in-situ, using techniques such as reflection high-energy electron diffraction 
(RHEED), ${ }^{[13,15,23]}$ these advances have made it possible to realize structures with the same level of control as in traditional semiconductor materials. Scientists now have the tools at their disposal to fabricate previously inconceivable structures and devices. The field of complex oxides is hence today an extremely intense area of research, ${ }^{[6-9,22,24]}$ with prodigious academic and commercial interest.

\subsection{Polar Catastrophe}

With the advent of layer-by-layer growth of complex oxides, the realization of a wide-range of new interfaces has become possible. One of the most intensively studied of these interfaces is that of two adjacent perovskite oxides. The perovskite crystal structure is shown in Figure 2 and is the structure of many complex metal oxides, including $\mathrm{SrTiO}_{3}$ and $\mathrm{LaAlO}_{3}$. The oxide perovskite structure $\mathrm{ABO}_{3}$ consists of alternating $\mathrm{AO}$ and $\mathrm{BO}_{2}(001)$ planes, as shown in Figure 2 (right and left respectively). In the case of $\mathrm{SrTiO}_{3}$ these planes are the chargeneutral $\mathrm{Sr}^{2+} \mathrm{O}^{2-}$ and $\mathrm{Ti}^{4+}\left(\mathrm{O}^{2-}\right)_{2}$ planes. In the $\mathrm{LaAlO}_{3}$ perovskite however the 001 planes are $\mathrm{La}^{3+} \mathrm{O}^{2-}$ and $\mathrm{Al}^{3+}\left(\mathrm{O}^{2-}\right)_{2}$, which have a net charge of $+q$ and $-q$ per two-dimensional unit cell respectively. When these two perovskites are joined at a 001 plane, the interface can either be $\mathrm{LaO} / \mathrm{TiO}_{2}$ [Figure 3] or $\mathrm{AlO}_{2} / \mathrm{SrO}$. Such interfaces possess an isolated positively or negatively charged plane which, in the absence of charge re-distribution, would give rise to the so-called polar-catastrophe ${ }^{[8,21-22]}$ in which the electrostatic potential within the structure diverges as the thickness of the polar perovskite increases. To avoid this unphysical situation, half an electron per 2-dimensional unit cell can be transferred across the interface from $\mathrm{LaO}$ to $\mathrm{TiO}_{2}$ as illustrated in Figure 3(b) (or from $\mathrm{SrO}$ to $\mathrm{AlO}_{2}$ ). Note that Figure 3 does not display the top $\mathrm{LaO}$ plane, which would be missing half an electron. Under these circumstances, electrons transferred across the interface are confined to a very small region vertically (simulations suggest approximately 2 unit cells ${ }^{[25-27]}$ ). Such highly-confined carriers are believed to exhibit a range of interesting phenomena such as strong correlations, ${ }^{[8]}$ high 
mobility 2-dimensional charge transport, ${ }^{[15-16]}$ extremely high (and tunable) electron density ${ }^{[15-16]}$ and superconductivity. ${ }^{[18]}$

\subsection{Two-Dimensional Charge Transport at Oxide-Oxide Interfaces}

In the first study of its kind, researchers from Bell Laboratories reported the formation of interfaces with atomic abruptness between the insulating perovskite oxides $\mathrm{SrTiO}_{3}$ and $\mathrm{LaAlO}_{3}{ }^{[14]}$ Charge transport studies revealed that whilst the $\mathrm{AlO}_{2} / \mathrm{SrO}$ interface was insulating, the $\mathrm{LaO} / \mathrm{TiO}_{2}$ interface was observed to be highly conducting, with Hall mobilites in excess of $10,000 \mathrm{~cm}^{2} \mathrm{~V}^{-1} \mathrm{~s}^{-1}$ measured at low temperatures. ${ }^{[15]}$ Magnetoresistance measurements provided evidence that carrier states in this system were quantized.

Further work on this structure later saw the demonstration of field-effect currentmodulation at the interface, ${ }^{[16]}$ leading the question to be raised as to whether such oxideoxide interfaces could potentially be exploited as an analogous system to traditional semiconductor heterostructures utilized in modulation-doped HEMTs $?^{[2,4]}$ However the carrier mobilities reported in these $\mathrm{SrTiO}_{3} / \mathrm{LaAlO}_{3}$ structures are still several orders of magnitude lower than those of traditional GaAs systems [Figure 4], or other two-dimensional systems such as graphene. ${ }^{[28]}$

Another oxide interface system which has since been studied is that of the wide-band gap semiconductor $\mathrm{ZnO}$ and $\mathrm{Mg}$-doped $\mathrm{ZnO} \cdot{ }^{[17,29-30]} \mathrm{ZnO}$ is one of the most highly studied oxide materials $^{[31]}$ and shows particular promise as an active layer in transparent, large-area thinfilm transistors. ${ }^{[6-7]} \mathrm{ZnO}$ generally crystallizes into a wurzite structure and although the interface cannot be considered in exactly the same manner as the $\mathrm{SrTiO}_{3} / \mathrm{LaAlO}_{3}$ perovskite interface, a highly local region of charge carriers is believed to also form at the $\mathrm{Mg}_{\mathrm{x}} \mathrm{Zn}_{1-\mathrm{x}} \mathrm{O} / \mathrm{ZnO}$ interface. ${ }^{[17]} \mathrm{ZnO}$ and $\mathrm{Mg}_{\mathrm{x}} \mathrm{Zn}_{1-\mathrm{x}} \mathrm{O}$ are piezoelectric materials, and in this 
case a strain-induced mismatch in their electrical polarization is believed to result in local charge accumulation [see Figure 5(a)]. ${ }^{[9,17]}$ By adjusting the magnesium content in the $\mathrm{Mg}_{\mathrm{x}} \mathrm{Zn}_{1-\mathrm{x}} \mathrm{O}$ layer, the carrier density at the interface can be adjusted [Figure 5(b)]. ${ }^{[17]} \mathrm{An}$ initial Hall mobility of $5,500 \mathrm{~cm}^{2} \mathrm{~V}^{-1} \mathrm{~s}^{-1}$ was measured in this system but, significantly, the quantum Hall effect was also observed [Figure 5(c)]. By improving material crystallinity and purity and by optimizing the magnesium content in the $\mathrm{Mg}_{\mathrm{x}} \mathrm{Zn}_{1-\mathrm{x}} \mathrm{O}$ layers, the quality of these heterointerface systems has been improved and mobilities up to $700,000 \mathrm{~cm}^{2} \mathrm{~V}^{-1} \mathrm{~s}^{-1}$ have been reported [see Figure 4(b)]. ${ }^{[32-33]}$ Furthermore, the fractional quantum Hall effect has also been recently observed in this system providing further evidence of the excellent structural quality of these interfaces. ${ }^{[32-34]}$

\subsection{Future Prospects for Oxide-Oxide Based Transistors}

With the broad range of intriguing phenomena already reported, ${ }^{[17-20,34]}$ it seems unlikely that electronics of the future will not involve oxide/oxide interfaces in some form. This field is clearly very much in its infancy but the number of potential applications of this system is truly mouth-watering. ${ }^{[8-9,22]}$ The strongly-correlated nature of electrons at these interfaces, whilst alluring, still demands a great deal of understanding. ${ }^{[35]}$ Indeed there also remains a great deal of debate as to the nature of the polar catastrophe ${ }^{[36]}$ or if it even takes place at all. ${ }^{[37]}$

As with other emergent transistor technologies ${ }^{[38-42]}$ the difficulty is not with the technology itself, but with its competition. Si-, Ge- and GaAs- based transistors still outperform all other technologies studied since, especially at room temperature (see Figure 4). None-the-less progress continues to be made in this field ${ }^{[33]}$ and only time will tell whether oxide/oxide interfaces can claim the throne of technology of choice for the manufacturing of high-mobility transistors for application in a range of high-end electronics. 


\section{Reduced Dimensions in Thin-Film Oxide Semiconductors}

Looking away from crystalline systems, a number of emerging material technologies are currently being explored for use as amorphous or poly-crystalline active layers for TFTs. Whilst amorphous silicon (a:Si) has traditionally been the standard material system for largearea electronics (such as in display backplanes), new semiconductor systems such as $\operatorname{organics}^{[43]}$ and metal oxides ${ }^{[6]}$ that can be fabricated using inexpensive processes and exhibit field-effect mobilities substantially in excess of a:Si $\left(\sim 0.5 \mathrm{~cm}^{2} / \mathrm{Vs}\right)$ [Figure 1(b)]. These systems are now gradually penetrating the electronic industry, attracting a great amount of both industrial and academic interest, while enabling new forms of electronics to be developed.

As opposed to the delocalized band-like transport observed in crystalline semiconductors, carrier transport in disordered systems is generally understood in terms of a hopping-based mechanism such as multiple-trapping and release ${ }^{[44-45]}$ or variable range hopping. ${ }^{[46]}$ Under these descriptions, the local hopping probability is understood to be exponentially dependent upon the distance between transport sites. ${ }^{[46]}$ As a result, roomtemperature charge carrier mobilities in disordered semiconductors tend to be at least an order of magnitude lower than those of crystalline semiconductors, ${ }^{[10,47]}$ and are more-often multiple orders of magnitude lower [Figure 1(a)]. ${ }^{[48-55]}$ Such semiconductor systems however can be grown using a diverse range of techniques, including those where the semiconductor is deposited in the liquid phase, for example via spin-coating, spray-coating or printing. ${ }^{[7,56]}$ These solution-based techniques are not only compatible with large-area, flexible substrates but also have the potential to vastly reduce product-manufacturing costs.

Whilst charge transport states in silicon and organic semiconductors are primarily highlydirectional hybridized $s p$-type orbitals, ${ }^{[57]}$ the relevant atomic orbitals for electron-transport in 
metal oxides are typically spherical $n s$-type orbitals, in which charge-transport properties are believed to be less sensitive to orbital orientation (Figure 6). ${ }^{[33,58]}$ It has thus been argued that the degree of long range structural order is of much less importance to the hopping rate, and hence charge-transport properties ${ }^{[59]}$ in n-type metal oxide semiconductors, providing an inherent advantage over conventional semiconductor technologies. Conversely, hole-transport in metal oxides is dominated by directional oxygen $2 p$ orbitals, resulting in substantially lower reported mobilities in disordered p-type oxide TFTs. ${ }^{[6]}$

With regards to solution-processed semiconductors, the major bottleneck for oxidebased materials has traditionally been the high processing temperatures required to convert precursor materials into semiconductors. ${ }^{[60-61]}$ This has resulted in solution-processed organic materials generally receiving much greater attention than solution-processed oxides. ${ }^{[43]}$ In the last few years however tremendous improvements have been made in reducing the processing temperature of solution-processed oxide TFTs via various processing techniques and/or using novel precursor systems, and solution-based oxide devices have now been demonstrated with processing temperatures around $200^{\circ} \mathrm{C}^{[51-52,62-63]}$ which is generally considered to be the ultimate thermal budget for flexible electronics.

\subsection{Heterostructure Metal Oxide Devices}

In order to provide feasible technologies for applications in next-generation ultra-highdefinition displays and high-performance large-area microelectronics, device physicists continue to push for higher-and-higher field effect mobilities [see Figure 1(b)], forcing them to turn to novel and innovative solutions. One of the most interesting and hence promising of these has been the multilayer TFT concept. Using atomic layer deposition (ALD), superlattice-based TFTs consisting of alternating layers of semiconducting $\mathrm{ZnO}$ and the insulator $\mathrm{Al}_{2} \mathrm{O}_{3}$ were recently reported. ${ }^{[64]}$ The mobility of these devices was found to increase 
from $4.8 \mathrm{~cm}^{2} \mathrm{~V}^{-1} \mathrm{~s}^{-1}$ to $27.8 \mathrm{~cm}^{2} \mathrm{~V}^{-1} \mathrm{~s}^{-1}$, and the on/off ratio from $10^{7}$ to $10^{9}$, when replacing a single-layer $\mathrm{ZnO}$ film with a $\mathrm{ZnO} / \mathrm{Al}_{2} \mathrm{O}_{3}$ superlattice as the active layer. As the thickness of each layer in the stack is reduced to approximately $5 \mathrm{~nm}$, the limit is approached where 2dimensional phenomena become relevant in the description of charge transport. Although ALD is not generally considered a particularly scalable or low-cost process, the formation of this structure is however a very important demonstration of the type of target structures that the disordered-semiconductor community seeks to fabricate with more scalable and hence cost-efficient deposition techniques.

Recently, a number of research groups have implemented similar approaches to enhance TFT performance by stacking different oxide semiconductors as the active channel with vacuum- ${ }^{[65-67]}$ or solution- ${ }^{[68-69]}$ based approaches. Yang-Yang et al recently reported bilayer heterostructure TFTs based on the solution-processed semiconductors InGaZnO (IGZO) and InSnZnO (ITZO). ${ }^{[69]}$ Although TFTs employing ITZO as the single active material exhibited high carrier concentrations, the on-off ratios were $\sim 10^{3}$, three orders of magnitude lower than single-layer IGZO devices $\left(\sim 10^{6}\right)$. By stacking IGZO on top of ITZO, not only was the electron mobility observed to increase from $1.6 \mathrm{~cm}^{2} \mathrm{~V}^{-1} \mathrm{~s}^{-1}$ for a single-layer IGZO device to $22 \mathrm{~cm}^{2} \mathrm{~V}^{-1} \mathrm{~s}^{-1}$ for a bilayer structure, but the devices also exhibited a high on-off ratio $\left(\sim 10^{7}\right)$. This dramatic improvement was attributed to the fact that the highly-dense ITZO bottom layer confines charge carriers within a thickness of $3 \mathrm{~nm}$, and the deeper Fermi level in IGZO increases the on-off ratio with respect to ITZO alone. Marks et al fabricated bilayer structures composed of a bottom indium oxide $\left(\operatorname{In}_{2} \mathrm{O}_{3}\right)$ layer and a top indium gallium oxide (IGO) layer via a solution-processed low-temperature combustion process. ${ }^{[68]}$ The structure was developed in an effort to combine the high on/off ratio of single-layer IGO TFTs $\left(\sim 10^{7}\right)$ with the high electron mobility of single-layer $\operatorname{In}_{2} \mathrm{O}_{3}$ TFTs $\left(\sim 2-4 \mathrm{~cm}^{2} \mathrm{~V}^{-1} \mathrm{~s}^{-1}\right)$ fabricated using the same process. The improvement is in this case attributed to the fact that the Femi level's 
close proximity of the conduction band minimum in the $\operatorname{In}_{2} \mathrm{O}_{3}$ layer could induce charge transfer and pre-fill empty traps in the IGO film.

\subsection{Evidence of Two-Dimensional Transport Behavior in Disordered Semiconductors}

In 2010 Chin et al fabricated $\mathrm{Mg}_{\mathrm{x}} \mathrm{Zn}_{1-\mathrm{x}} \mathrm{O} / \mathrm{ZnO}$ heterostructures via radio-frequency (rf) sputtering $^{[70]}$ in an attempt to produce a disordered-semiconductor analogue of the muchstudied, crystalline $\mathrm{Mg}_{\mathrm{x}} \mathrm{Zn}_{1-\mathrm{x}} \mathrm{O} / \mathrm{ZnO}$ interfaces described in Section 2.3. ${ }^{[17]}$ Hall mobilities in this system were observed to be approximately temperature-independent, which was attributed to the polarization-induced formation of a 2DEG at the interface between the two semiconductors. In an extension of this study, ${ }^{[71]}$ analogous $\mathrm{Mg}_{\mathrm{x}} \mathrm{Zn}_{1-\mathrm{x}} \mathrm{O} / \mathrm{ZnO}$ heterostructures TFTs were also fabricated. An increase in electron field-effect mobility of a $\mathrm{Mg}_{0.2} \mathrm{Zn}_{0.8} \mathrm{O} / \mathrm{ZnO}$ TFT with respect to an equivalent $\mathrm{ZnO}$ TFT (from $2.3 \mathrm{~cm}^{2} \mathrm{~V}^{-1} \mathrm{~s}^{-1}$ to 9.1 $\mathrm{cm}^{2} \mathrm{~V}^{-1} \mathrm{~s}^{-1}$ ) was attributed to 2-dimensional charge-transport effects. Whilst this data is rather preliminary, the concept of 2-dimensional charge transport in polycrystalline or amorphous films in an intriguing one.

The disordered equivalent of the $\mathrm{LaAlO}_{3} / \mathrm{SrTiO}_{3}$-type interface has also been investigated. ${ }^{[72]}$ Atomically flat (001)-terminated $\mathrm{LaAlO}_{3}$ samples were grown via PLD, after which disordered $\mathrm{LaAlO}_{3}, \mathrm{SrTiO}_{3}$ or yttria-stabilized zirconia (YSZ), all of which are electrically insulating, was deposited on top. These interfaces were found to be metallic, with a conductivity that increased with decreasing temperature. However it was observed that if the amorphous component of the interface was $\mathrm{La}_{7 / 8} \mathrm{Sr}_{1 / 8} \mathrm{MnO}_{3}$ (LSMO), the structure was insulating.

Although the possibility of strongly-correlated electrons in a disordered system seems unlikely, the existence of quantized energy states is a notion worth interrogating ${ }^{[73]}$. The 
Schrödinger equation dictates that carriers spatially confined to a potential of small-enough dimensions will have access to discreet energy states rather than continuum, as is the case for carriers in a bulk material. Were one to engineer a potential well of appropriate dimensions from polycrystalline or amorphous materials, then regardless of structural roughness or disorder, carriers confined in the well should still be expected to possess discreet energies. In a potential well with a finite roughness an ensemble of electrons would however be expected to experience a distribution of well widths and hence available energies. ${ }^{[74]}$ If the well-width distribution is known then one can evaluate the probability of each electron in the system experiencing a well with a certain width, and hence the probability of it having access to certain energies.

In our recent study, such a distribution was calculated for an infinite potential well with a Gaussian thickness distribution (see Figure 7). ${ }^{[7]}$ Although there is clearly a broadening of available energies as one goes from a perfect quantum well to that formed of structurally rough semiconductors, a large range of forbidden energies clearly exists, suggesting that one should indeed expect quantization to take place in semiconductors of finite, but low, roughness. In the past, quantization within GaAs/AlGaAs systems has been studied optically. ${ }^{[75]}$ As a semiconductor makes the transition from bulk to 2-dimensional, the first available conduction (valance) band state increases (decreases) as the quantization of permitted energies takes place. The result is a blue-shift in the optical absorption spectrum of the system. In 2012 Hosono et al. reported the fabrication of an amorphous oxide superlattice structure $^{[76]}$ via rf-sputtering. The structure consisted of alternating IGZO semiconductor and $\mathrm{Ga}_{2} \mathrm{O}_{3}$ barrier layers, and a clear blue shift (shorter wavelengths) in the optical absorption spectra was observed as the layer IGZO layer thicknesses was reduced. By employing the Kronig-Penney model, the measured change in optical band-gap was found to strongly match that expected for such a superlattice. In our recent study, a similar optical blue-shift was also 
observed in single films of $\mathrm{ZnO}$ deposited from solution-phase at low temperatures $\left(<200{ }^{\circ} \mathrm{C}\right)$ on quartz substrates. ${ }^{[74]}$ The latter observation is of particular importance as it demonstrates the ability to grow low-dimensional metal oxide systems using simple and highly scalable deposition methods that are compatible with inexpensive and temperature-sensitive substrate materials such as plastic.

For conventional group IV and III-V electronics, 2DEGs can also be formed via electrostatic confinement. ${ }^{[4]}$ In addition to the novel phenomena arising from 2-dimensional charge-transport, modulation-doped heterojunction transistor structures successfully disentangles the transport within the un-doped semiconductor and the intentionally doped part of the semiconductor vertically. The result is a doped transporting channel, without the scattering processes associated with the presence of the dopant atom sites, and subsequent superior charge transport as compared to bulk-doped semiconductors. Frenzel et al fabricated metal-semiconductor field-effect transistors (MESFETs) employing an $\mathrm{Mg}_{0.1} \mathrm{Zn}_{0.9} \mathrm{O}: \mathrm{Ga} / \mathrm{ZnO} / \mathrm{Mg}_{0.1} \mathrm{Zn}_{0.9} \mathrm{O}: \mathrm{Ga}$ quantum well, inspired by traditional HEMTs. ${ }^{[77]}$ Although a high transconductance was found in these ZnO-based MESFETs, no functional devices were measured, owing to the high barrier of the 100-nm thick MgZnO:Ga layers, prohibiting carrier injection from the source and drain electrodes.

On the basis of this discussion and the body of experimental evidence reported to date, it appears that the possibility of forming two-dimensional charge transport systems in TFTs may require careful tuning of the quantized energy levels in low-dimensional semiconducting layers as well as use of suitable device architectures. Recently our group demonstrated a simple approach that allows such optimized heterointerface systems to be constructed using various semiconducting oxides, such as $\mathrm{ZnO}, \mathrm{In}_{2} \mathrm{O}_{3}$ and $\mathrm{Ga}_{2} \mathrm{O}_{3}$, processed entirely from solution at low temperatures $\left(180-200{ }^{\circ} \mathrm{C}\right) .{ }^{[78]}$ Through a careful choice and combination of 
the metal oxides, the notable difference in energy levels between $\mathrm{ZnO}$ and $\operatorname{In}_{2} \mathrm{O}_{3}$ could induce charge migration towards the ultra-thin $\operatorname{In}_{2} \mathrm{O}_{3}$ layer, which not only serves as an excellent charge-transporting layer but also exhibits clear energy quantization (Figure 8). Characterisation of solution grown oxide heterojunctions and multilayer superlattices [Figure 9(a)] using X-ray reflectivity (XRR) [Figure 9(b)], atomic force microscopy (AFM) [Figure 9(c)] and time-of-flight secondary ion-mass spectroscopy (TOF-SIMS) [Figure 9(d)] measurements, revealed that multilayer oxide structures with smooth and chemically sharp heterointerfaces can indeed be grown from solution at low temperatures.

Field-effect transistors based on single layer $\mathrm{ZnO}$ and $\operatorname{In}_{2} \mathrm{O}_{3}$ semiconductors were found to exhibit electron mobilities in the range $2-4 \mathrm{~cm}^{2} \mathrm{~V}^{-1} \mathrm{~s}^{-1}{ }^{[80]}$ However, when the discrete and ultra-thin oxide layers were combined to form complex layered channel structures, such as heterojunctions and quasi-superlattices (QSLs) [Figure 10(a)], the electron mobility of the resulting TFTs was found to increase substantially to values ranging between $10-50 \mathrm{~cm}^{2} \mathrm{~V}^{-1} \mathrm{~s}^{-1}$ with on/off ratios $>10^{5}$ [see Figure 10(b-c)]. Furthermore, temperature dependent transport studies performed in these devices showed that the electron mobility in single layer $\mathrm{ZnO}$ and $\mathrm{In}_{2} \mathrm{O}_{3}$ TFTs reduces with decreasing temperature while in the case of QSL-I and QSL-III TFTs [Figure 10(a)] it remained largely temperature independent [Figure 10(c)]. This band-like transport behavior was attributed to the existence of a 2DEG-like system formed at the carefully engineered low-dimensional oxide heterointerfaces and particularly the $\mathrm{In}_{2} \mathrm{O}_{3}$ side of the interfaces (Figure 11). On the basis of these results the authors argued that the QSL-based TFT concept is generic and could in principle be extend to a range of other oxide semiconductor combinations and fabrication methods (e.g. sputtering, atomic layer deposition, spray pyrolysis and roll-to-roll), and provide a viable approach for overcoming device performance limitation due to the intrinsic properties of the semiconductors used. ${ }^{[80]}$ 
Although by no-means definitive, evidence is mounting that two-dimensional transport phenomena could indeed be exploited in these disordered/polycrystalline semiconductor systems. If this is indeed possible then the commercial applications that can potentially be enabled by exploiting this fundamental physical phenomenon are both vast and exceedingly novel. In addition to analogs of modulation-doped HEMTs, ${ }^{[2]}$ one can envision a number of other quantum-well-based devices such as resonant-tunneling diodes, ${ }^{[79]}$ complex but simple to implement thermoelectrics ${ }^{[80-81]}$ or even quantum-cascade lasers ${ }^{[82]}$ being designed using this highly versatile and inexpensive "tool-kit" of materials and fabrication processes.

\section{Conclusions}

We have presented a brief overview of the technological relevance of certain two-dimensional charge transport phenomena occurring at heterointerfaces formed between functional electronic materials, with emphasis on metal oxides, and likely future research directions. Two-dimensional charge transport channels at high quality oxide heterointerfaces grown via pulsed-laser deposition or molecular beam epitaxy have been shown to exhibit very high charge carrier mobilities and clear gate-induced electric field-effect modulation. However, due to the exceptional performance of incumbent crystalline semiconductor technologies (e.g. $\mathrm{Si}, \mathrm{GaAs}$ ), completion in the area of high-end electronics (with the exception of highfrequency electronics) remains fierce and the authors would argue that substantial progress still remains to be made before these traditional technologies are replaced. On the other hand, recent progress in the field of amorphous/polycrystalline metal oxide thin-film transistors may well prove to be much more disruptive for a host of large-area electronics applications. This is primarily due to the fact that unlike incumbent silicon-based TFT technologies, metal oxides are compatible with inexpensive, high-throughput and large-area compatible growth techniques such as solution-deposition and sputtering. Furthermore, electron mobility values 
obtained in oxides and their devices now comfortably exceed those of competing technologies based on organics and amorphous silicon. Most importantly, however, recent studies have shown that the performance of certain oxide TFTs can be significantly enhanced through the use of carefully engineered oxide heterointerfaces grown via simple and scalable deposition techniques. Although not yet fully understood, the enhanced performance is argued to originate from the low-dimensional charge transport phenomena occurring at the vicinity of the heterointerfaces(s). Although experimental evidence of the latter is somewhat preliminary, the potential for novel, high-impact research remains substantial, and these concepts clearly demand interrogation.

\section{Acknowledgements}

J.L. and T.D.A. are grateful to the European Research Council (ERC) AMPRO project no. 280221 for financial support.

${ }^{\dagger}$ These authors contributed equally to this work.

Received: ((will be filled in by the editorial staff))

Revised: ((will be filled in by the editorial staff))

Published online: ((will be filled in by the editorial staff)) 


\section{Authors Biographies}

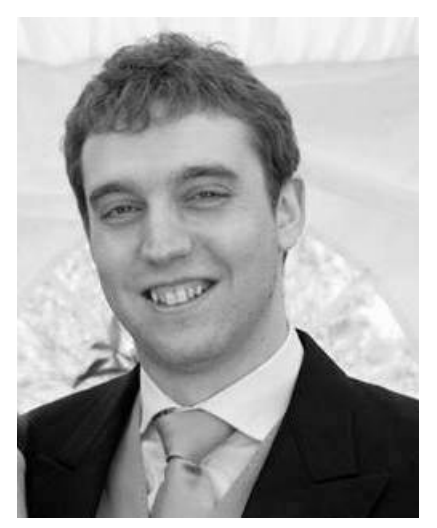

John Labram received his MPhys degree in Physics from The University of Warwick in 2008 and his $\mathrm{PhD}$ in Experimental Physics from Imperial College London in 2012, under the supervision of Professor Thomas Anthopoulos. During his PhD, John focused on ambipolar organic field-effect transistors for both photo-transistor applications and to study the relationship between morphology and charge-transport in polymer:fullerene blends. Since 2013 John worked as a postdoctoral research associate under Professor Thomas Anthopoulos at Imperial College London. Here his interests are two-dimensional effects in solutionprocessed metal oxide semiconductors.

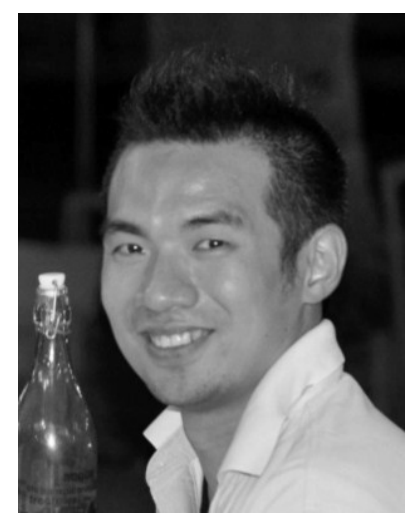

Yen-Hung Lin received his B.S. in Bioenvironmental System Engineering (2005) and M.S. in Photonics and Optoelectronics (2007) from National Taiwan University. Since 2008 he worked at AU Optronics (Taiwan) as a senior engineer in the R\&D department. In 2010 he enrolled to Imperial College London (UK) and obtained his M.Sc. in Optics and Photonics 
(2011) from the Department of Physics. He subsequently began his doctoral work in Experimental Solid-State Physics at the same university under the supervision of Professor Thomas Anthopoulos. His current research focuses on development of large-area flexible electronics based on solution-processable metal oxide and hybrid material systems.

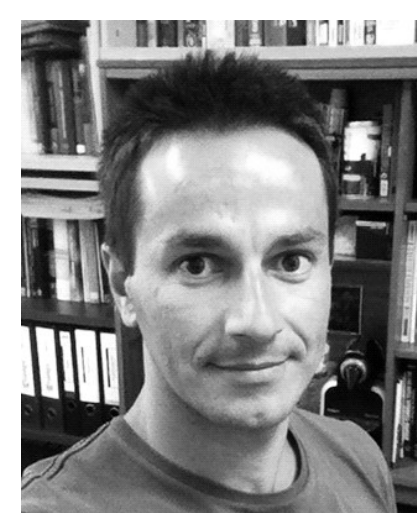

Thomas Anthopoulos received his B.Eng. degree and Ph.D., from Staffordshire University (UK). He then moved to University of St. Andrews (UK) where he worked on organic lightemitting diodes followed by an appointment at Philips Research Laboratories (The Netherlands) where he focused on ambipolar charge transport processes in organic semiconductors and their application in transistors and integrated circuits. In 2006 he joined the Department of Physics at Imperial College London (UK) where he is currently a Professor of Experimental Physics. His current research interest is focused on novel optoelectronic materials, scalable patterning methods for large-area nano-electronics and the physics of charge transport in novel material systems and devices. 


\section{Table of Contents Entry}

Exotic charge transport phenomena have been reported for several two-dimensional semiconducting systems and their devices. Recent experimental results suggest that similar phenomena can be achieved in metal oxide-based systems. In this article, an overview of different transistor technologies the operation of which relies on low-dimensional charge transport is given and potential future research directions in the area of thin-film transistors are discussed.

Keywords: energy quantization, metal oxides, semiconductors, transistors, heterostructures, two-dimensional charge transport, solution processing

John G. Labram ${ }^{\dagger}$, Yen-Hung Lin ${ }^{\dagger}$, Thomas D. Anthopoulos ${ }^{*}$

Title: Exploring Two-Dimensional Transport Phenomena in Metal Oxide Heterointerfaces for Next Generation High-Performance Thin-Film Transistor Technologies

\section{TOC}
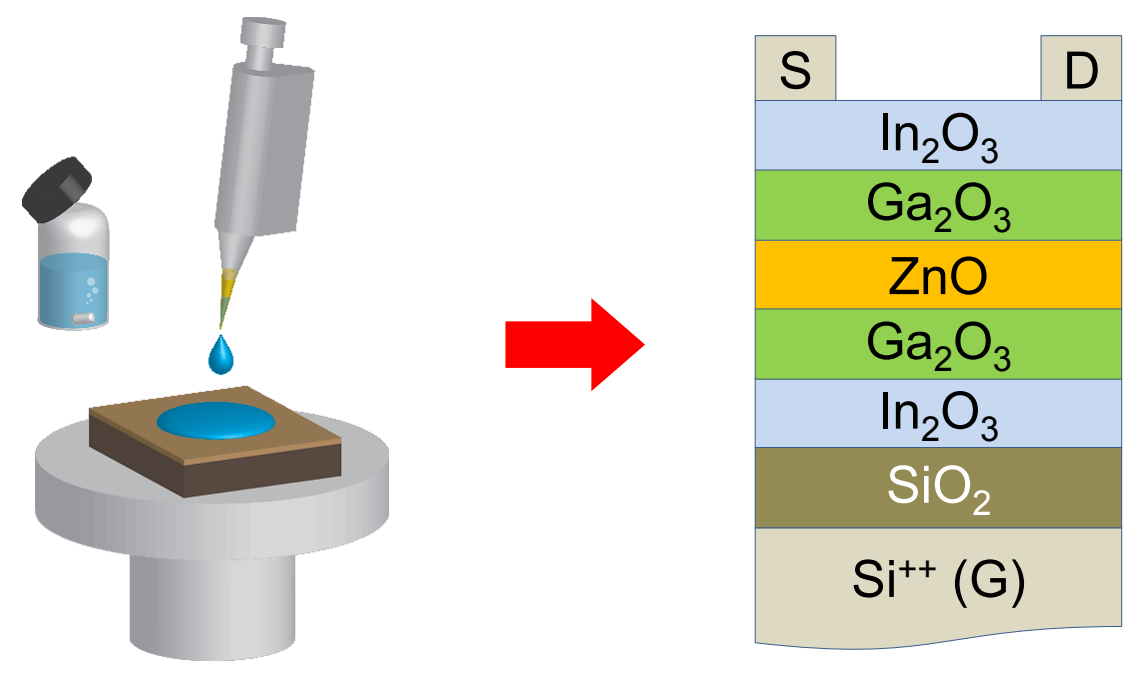


\section{Reference}

[1] G. E. Moore, Proceedings of the IEEE 1998, 86, 82-85.

[2] R. Dingle, H. L. Störmer, A. C. Gossard, W. Wiegmann, Appl. Phys. Lett. 1978, 33, 665-667.

[3] T. Ando, A. B. Fowler, F. Stern, Rev. Mod. Phys. 1982, 54, 437-672.

[4] T. J. Drummond, W. T. Masselink, H. Morkoc, Proceedings of the IEEE 1986, 74, 773-822.

[5] D. G. Schlom, L. N. Pfeiffer, Nat Mater 2010, 9, 881-883.

[6] E. Fortunato, P. Barquinha, R. Martins, Adv. Mater. 2012, 24, 2945-86.

[7] S. R. Thomas, P. Pattanasattayavong, T. D. Anthopoulos, Chem Soc Rev 2013, 42, 6910-6923.

[8] J. Mannhart, D. G. Schlom, Science 2010, 327, 1607-1611.

[9] H. Y. Hwang, Y. Iwasa, M. Kawasaki, B. Keimer, N. Nagaosa, Y. Tokura, Nat Mater 2012, 11, 103-113.

[10] P. K. Nayak, M. N. Hedhili, D. Cha, H. N. Alshareef, Appl Phys Lett 2013, 103, -.

[11] D. Dijkkamp, T. Venkatesan, X. D. Wu, S. A. Shaheen, N. Jisrawi, Y. H. Min - Lee, W. L. McLean, M. Croft, Appl Phys Lett 1987, 51, 619-621.

[12] D. G. Schlom, J. N. Eckstein, E. S. Hellman, S. K. Streiffer, J. S. Harris, M. R. Beasley, J. C. Bravman, T. H. Geballe, C. Webb, K. E. von Dessonneck, F. Turner, Appl Phys Lett 1988, 53, 1660-1662.

[13] D.-W. Kim, D.-H. Kim, B.-S. Kang, T. W. Noh, D. R. Lee, K.-B. Lee, Appl Phys Lett 1999, 74, 2176-2178.

[14] A. Ohtomo, D. A. Muller, J. L. Grazul, H. Y. Hwang, Nature 2002, 419, 378-380.

[15] A. Ohtomo, H. Y. Hwang, Nature 2004, 427, 423-426.

[16] S. Thiel, G. Hammerl, A. Schmehl, C. W. Schneider, J. Mannhart, Science 2006, 313, 1942-1945. 
[17] A. Tsukazaki, A. Ohtomo, T. Kita, Y. Ohno, H. Ohno, M. Kawasaki, Science 2007, 315, 1388-1391.

[18] N. Reyren, S. Thiel, A. D. Caviglia, L. F. Kourkoutis, G. Hammerl, C. Richter, C. W. Schneider, T. Kopp, A.-S. Rüetschi, D. Jaccard, M. Gabay, D. A. Muller, J.-M. Triscone, J. Mannhart, Science 2007, 317, 1196-1199.

[19] A. Gozar, G. Logvenov, L. F. Kourkoutis, A. T. Bollinger, L. A. Giannuzzi, D. A. Muller, I. Bozovic, Nature 2008, 455, 782-785.

[20] G. Logvenov, A. Gozar, I. Bozovic, Science 2009, 326, 699-702.

[21] N. Nakagawa, H. Y. Hwang, D. A. Muller, Nat Mater 2006, 5, 204-209.

[22] J. Mannhart, D. H. A. Blank, H. Y. Hwang, A. J. Millis, J.-M. Triscone, Mrs Bull 2008, $33,1027-1034$.

[23] G. J. H. M. Rijnders, G. Koster, D. H. A. Blank, H. Rogalla, Appl Phys Lett 1997, 70, 1888-1890.

[24] R. Jany, C. Richter, C. Woltmann, G. Pfanzelt, B. Förg, M. Rommel, T. Reindl, U. Waizmann, J. Weis, J. A. Mundy, D. A. Muller, H. Boschker, J. Mannhart, Adv. Mater. Interfaces 2014, 1, 1300031.

[25] Z. S. Popovic, S. Satpathy, Phys Rev Lett 2005, 94, 176805.

[26] M. S. Park, S. H. Rhim, A. J. Freeman, Phys Rev B 2006, 74, 205416.

[27] R. Pentcheva, W. E. Pickett, Phys Rev Lett 2007, 99, 016802.

[28] A. K. Geim, K. S. Novoselov, Nat Mater 2007, 6, 183-191.

[29] M. Brandt, H. von Wenckstern, G. Benndorf, H. Hochmuth, M. Lorenz, M. Grundmann, Thin Solid Films 2009, 518, 1048-1052.

[30] A. Gold, Appl Phys Lett 2010, 96, -.

[31] D. C. Look, Materials Science and Engineering: B 2001, 80, 383-387.

[32] Y. Kozuka, A. Tsukazaki, D. Maryenko, J. Falson, S. Akasaka, K. Nakahara, S. Nakamura, S. Awaji, K. Ueno, M. Kawasaki, Phys Rev B 2011, 84, 033304. 
[33] F. Joseph, M. Denis, K. Yusuke, T. Atsushi, K. Masashi, Applied Physics Express 2011, 4, 091101.

[34] A. Tsukazaki, S. Akasaka, K. Nakahara, Y. Ohno, H. Ohno, D. Maryenko, A. Ohtomo, M. Kawasaki, Nat. Mater. 2010, 9, 889-893.

[35] S. Okamoto, A. J. Millis, Nature 2004, 428, 630-633.

[36] Z. S. Popović, S. Satpathy, R. M. Martin, Phys Rev Lett 2008, 101, 256801.

[37] M. L. Reinle-Schmitt, C. Cancellieri, D. Li, D. Fontaine, M. Medarde, E. Pomjakushina, C. W. Schneider, S. Gariglio, P. Ghosez, J. M. Triscone, P. R. Willmott, Nat Commun 2012, 3, 932.

[38] C. K. Chiang, C. R. Fincher, Y. W. Park, A. J. Heeger, H. Shirakawa, E. J. Louis, S. C. Gau, A. G. MacDiarmid, Phys Rev Lett 1977, 39, 1098-1101.

[39] H. W. Kroto, J. R. Heath, S. C. O'Brien, R. F. Curl, R. E. Smalley, Nature 1985, 318, 162-163.

[40] S. Iijima, Nature 1991, 354, 56-58.

[41] K. S. Novoselov, A. K. Geim, S. V. Morozov, D. Jiang, Y. Zhang, S. V. Dubonos, I. V. Grigorieva, A. A. Firsov, Science 2004, 306, 666-669.

[42] B. Radisavljevic, A. Radenovic, J. Brivio, V. Giacometti, A. Kis, Nat. Nano. 2011, 6, $147-150$

[43] J. Zaumseil, H. Sirringhaus, Chem Rev 2007, 107, 1296-1323.

[44] P. W. Anderson, Physical Review 1958, 109, 1492.

[45] N. F. Mott, Philos. Mag. B-Phys. Condens. Matter Stat. Mech. Electron. Opt. Magn. Prop. 1981, 43, 941-942.

[46] M. C. J. M. Vissenberg, M. Matters, Phys Rev B 1998, 57, 12964-12967.

[47] Y. Yuan, G. Giri, A. L. Ayzner, A. P. Zoombelt, S. C. B. Mannsfeld, J. Chen, D. Nordlund, M. F. Toney, J. Huang, Z. Bao, Nat Commun 2014, 5. 
[48] H. Bronstein, Z. Chen, R. S. Ashraf, W. Zhang, J. Du, J. R. Durrant, P. Shakya Tuladhar, K. Song, S. E. Watkins, Y. Geerts, M. M. Wienk, R. A. J. Janssen, T. Anthopoulos, H. Sirringhaus, M. Heeney, I. McCulloch, J Am Chem Soc 2011, 133, 3272-3275.

[49] J. Li, Y. Zhao, H. S. Tan, Y. Guo, C.-A. Di, G. Yu, Y. Liu, M. Lin, S. H. Lim, Y. Zhou, H. Su, B. S. Ong, Sci. Rep. 2012, 2.

[50] H.-R. Tseng, L. Ying, B. B. Y. Hsu, L. A. Perez, C. J. Takacs, G. C. Bazan, A. J. Heeger, Nano Lett 2012, 12, 6353-6357.

[51] Y.-H. Lin, H. Faber, K. Zhao, Q. Wang, A. Amassian, M. McLachlan, T. D. Anthopoulos, Adv Mater 2013, 25, 4340-4346.

[52] K. K. Banger, Y. Yamashita, K. Mori, R. L. Peterson, T. Leedham, J. Rickard, H. Sirringhaus, Nat. Mater. 2011, 10, 45-50.

[53] K. Nomura, H. Ohta, A. Takagi, T. Kamiya, M. Hirano, H. Hosono, Nature 2004, 432, 488-492.

[54] T. Kamiya, K. Nomura, H. Hosono, J. Display Technol. 2009, 5, 462-467.

[55] T. Kamiya, K. Nomura, H. Hosono, J. Display Technol. 2009, 5, 468-483.

[56] J. Smith, R. Hamilton, I. McCulloch, N. Stingelin-Stutzmann, M. Heeney, D. D. C. Bradley, T. D. Anthopoulos, J Mater Chem 2010, 20, 2562-2574.

[57] J. Clayden, N. Greeves, S. Warren, Organic Chemistry, OUP Oxford, 2012.

[58] S. Narushima, M. Orita, M. Hirano, H. Hosono, Phys. Rev. B 2002, 66, 035203035211.

[59] T. Kamiya, H. Hosono, NPG Asia Mater. 2010, 2, 15-22.

[60] A. Bashir, P. H. Wöbkenberg, J. Smith, J. M. Ball, G. Adamopoulos, D. D. C. Bradley, T. D. Anthopoulos, Adv Mater 2009, 21, 2226-2231.

[61] G. Adamopoulos, A. Bashir, S. Thomas, W. P. Gillin, S. Georgakopoulos, M. Shkunov, M. A. Baklar, N. Stingelin, R. C. Maher, L. F. Cohen, D. D. C. Bradley, T. D. Anthopoulos, Adv Mater 2010, 22, 4764-4769. 
[62] R. Theissmann, S. Bubel, M. Sanlialp, C. Busch, G. Schierning, R. Schmechel, Thin Solid Films 2011, 519, 5623-5628.

[63] S. Jeong, J. Moon, J. Mater. Chem. 2012, 22, 1243-1250.

[64] C. H. Ahn, K. Senthil, H. K. Cho, S. Y. Lee, Sci. Rep. 2013, 3.

[65] M. Nag, A. Chasin, M. Rockele, S. Steudel, K. Myny, A. Bhoolokam, A. Tripathi, B. van der Putten, A. Kumar, J.-L. van der Steen, J. Genoe, F. Li, J. Maas, E. van Veenendaal, G. Gelinck, P. Heremans, J. Soc. Info. Display 2013, 21, 129-136.

[66] H. A. Al-Jawhari, J. A. Caraveo-Frescas, M. N. Hedhili, H. N. Alshareef, ACS Appl. Mater. Interfaces 2013, 5, 9615-9619.

[67] G. X. Liu, A. Liu, F. K. Shan, Y. Meng, B. C. Shin, E. Fortunato, R. Martins, Appl. Phys. Lett. 2014, 105, 113509.

[68] X. Yu, N. Zhou, J. Smith, H. Lin, K. Stallings, J. Yu, T. J. Marks, A. Facchetti, ACS Appl. Mater. Interfaces 2013, 5, 7983-7988.

[69] Y. S. Rim, H. Chen, X. Kou, H.-S. Duan, H. Zhou, M. Cai, H. J. Kim, Y. Yang, Adv. Mater. 2014, 26, 4273-4278.

[70] H.-A. Chin, I.-C. Cheng, C.-I. Huang, Y.-R. Wu, W.-S. Lu, W.-L. Lee, J. Z. Chen, K.C. Chiu, T.-S. Lin, J Appl Phys 2010, 108, -.

[71] I.-C. Cheng, B.-S. Wang, H.-H. Hou, J.-Z. Chen, ECS Trans. 2013, 50, 83-93.

[72] Y. Chen, N. Pryds, J. e. E. Kleibeuker, G. Koster, J. Sun, E. Stamate, B. Shen, G. Rijnders, S. Linderoth, Nano Lett 2011, 11, 3774-3778.

[73] F. Domínguez-Adame, A. Sánchez, E. Diez, Phys. Rev. B 1994, 50, 17736-17739.

[74] J. G. Labram, Y.-H. Lin, K. Zhao, R. Li, S. R. Thomas, J. Semple, M. Androulidaki, L. Sygellou, M. McLachlan, E. Stratakis, A. Amassian, T. D. Anthopoulos, Adv. Funct. Mater. 2015, 25, 1727-1736.

[75] R. Dingle, W. Wiegmann, C. H. Henry, Phys Rev Lett 1974, 33, 827-830.

[76] K. Abe, K. Nomura, T. Kamiya, H. Hosono, Phys. Rev. B 2012, 86, 081202. 
[77] H. Frenzel, A. Lajn, H. von Wenckstern, M. Lorenz, F. Schein, Z. Zhang, M. Grundmann, Adv. Mater. 2010, 22, 5332-5349.

[78] Y.-H. Lin, H. Faber, J. G. Labram, E. Stratakis, L. Sygellou, E. Kymakis, N. A. Hastas, R. Li, K. Zhao, A. Amassian, N. D. Treat, M. McLachlan, T. D. Anthopoulos, Adv. Sci. 2015, DOI: $10.1002 / \mathrm{advs} .201500058$.

[79] L. L. Chang, L. Esaki, R. Tsu, Appl Phys Lett 1974, 24, 593-595.

[80] L. D. Hicks, M. S. Dresselhaus, Phys Rev B 1993, 47, 12727-12731.

[81] G. J. Snyder, E. S. Toberer, Nat Mater 2008, 7, 105-114.

[82] J. Faist, F. Capasso, D. L. Sivco, C. Sirtori, A. L. Hutchinson, A. Y. Cho, Science 1994, 264, 553-556. 


\section{Figures}
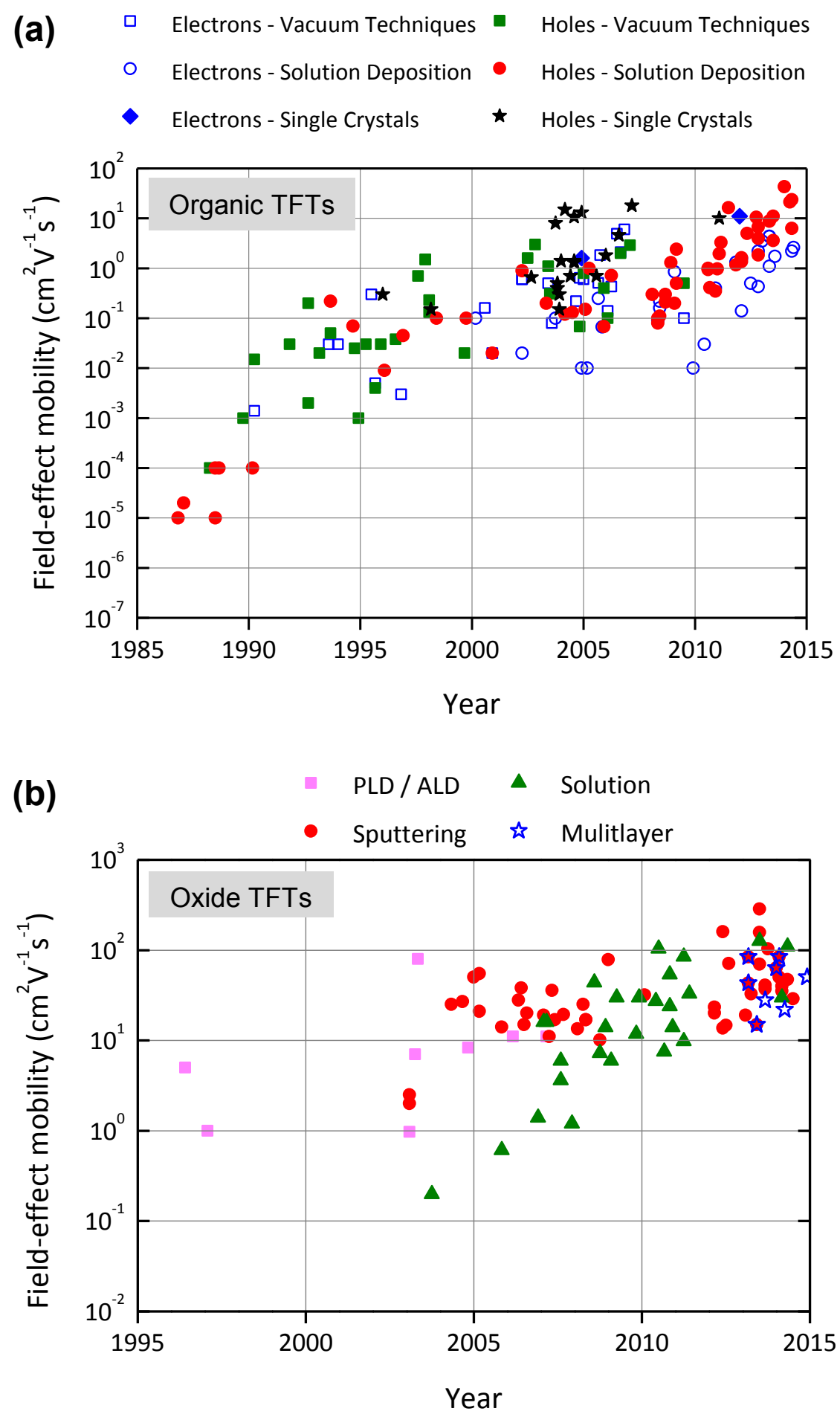

Figure 1. Highest reported field-effect charge carrier mobility as a function of publication date for a number of significant reports in the fields of; (a) organics and (b) metal oxide thinfilm transistors. All data in (b) represent electron field-effect mobility values. 

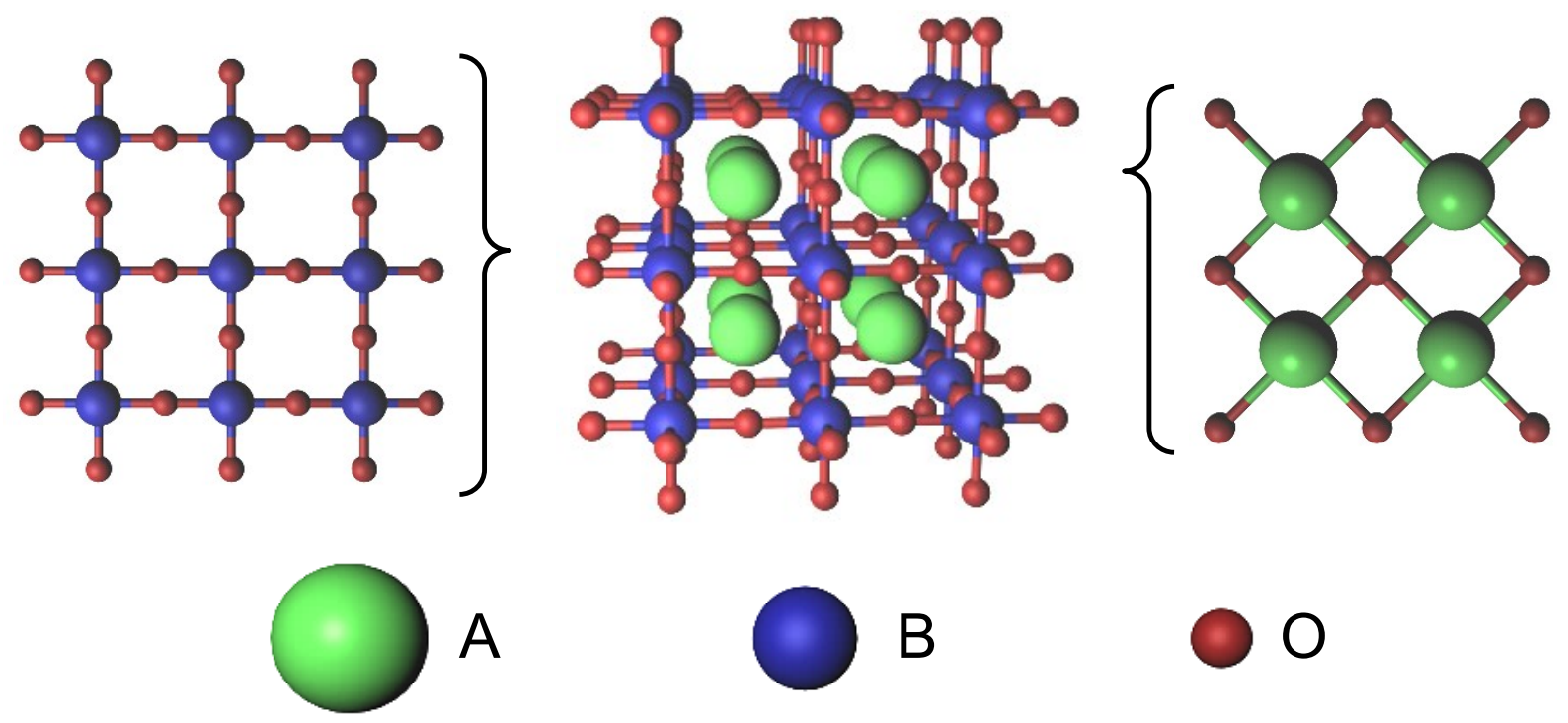

A
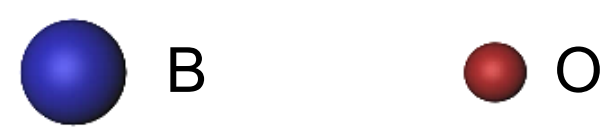

Figure 2. Centre: Schematic representation of perovskite crystal structure $\left(\mathrm{ABO}_{3}\right)$ formed of alternating (001) planes of $\mathrm{BO}_{2}$ (left) and $\mathrm{AO}$ (right). 
(a)

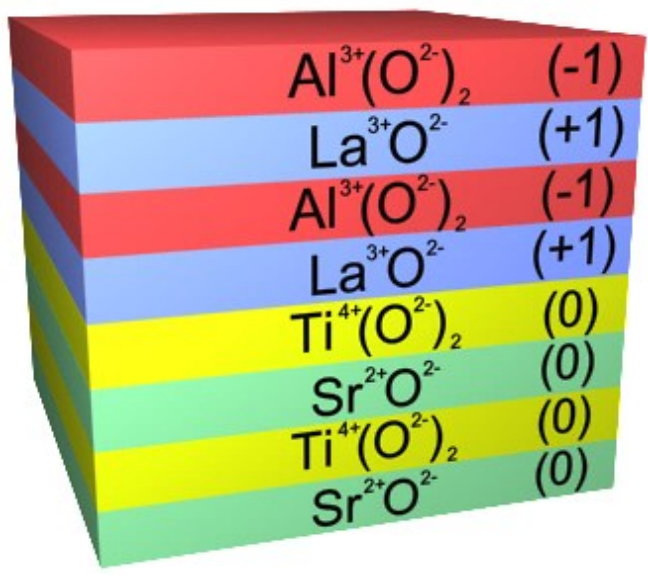

(b)

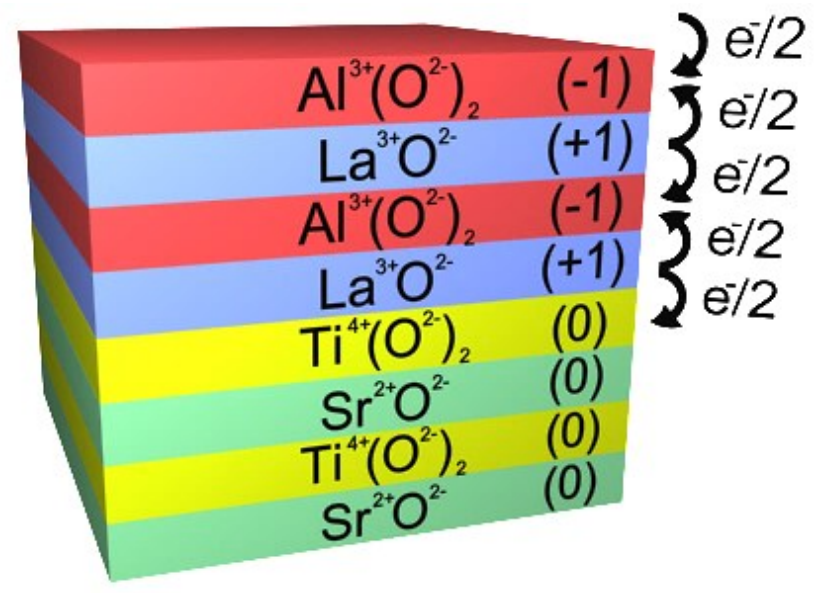

Figure 3. Illustration of charge compensation process in atomically abrupt interface between (001) planes of $\mathrm{LaAlO}_{3}$ and $\mathrm{SrTiO}_{3}$ perovskites. (a) The $\mathrm{SrTiO}_{3}$ structure is formed of alternating charge neutral (001) planes of $\mathrm{Sr}^{2+} \mathrm{O}^{2-}$ and $\mathrm{Ti}^{4+}\left(\mathrm{O}^{2-}\right)_{2}-$ both labelled (0) to indicate their charge neutrality. $\mathrm{LaAlO}_{3}$ however consists of planes of $\mathrm{La}^{3+} \mathrm{O}^{2-}$ and $\mathrm{Al}^{3+}\left(\mathrm{O}^{2-}\right)_{2}$, with net charges of $+q$ and $-\mathrm{q}$ per two-dimensional unit cell respectively. Positive and negatively charged planes are labelled as $(+1)$ and $(-1)$ respectively. If the interface between the two perovskites is $\mathrm{Ti}^{4+}\left(\mathrm{O}^{2-}\right)_{2} / \mathrm{La}^{3+} \mathrm{O}^{2-}$, as shown, then an isolated positively charged plane is left at the interface. In the absence of charge re-distribution this would lead to an electrostatic potential that diverges as the thickness of the polar $\mathrm{LaAlO}_{3}$ perovskite increases. $^{[21]}$ (b) To avoid this unphysical "polar catastrophe" situation it is believed that half an electron per 2-dimensional unit cell is transferred across the interface from the $\mathrm{La}^{3+} \mathrm{O}^{2-}$ plane to the $\mathrm{Ti}^{4+}\left(\mathrm{O}^{2-}\right)_{2}$ plane as shown. Such a re-distribution of charge carriers would result in highly spatially-confined free carriers at the interface between the two oxides. 

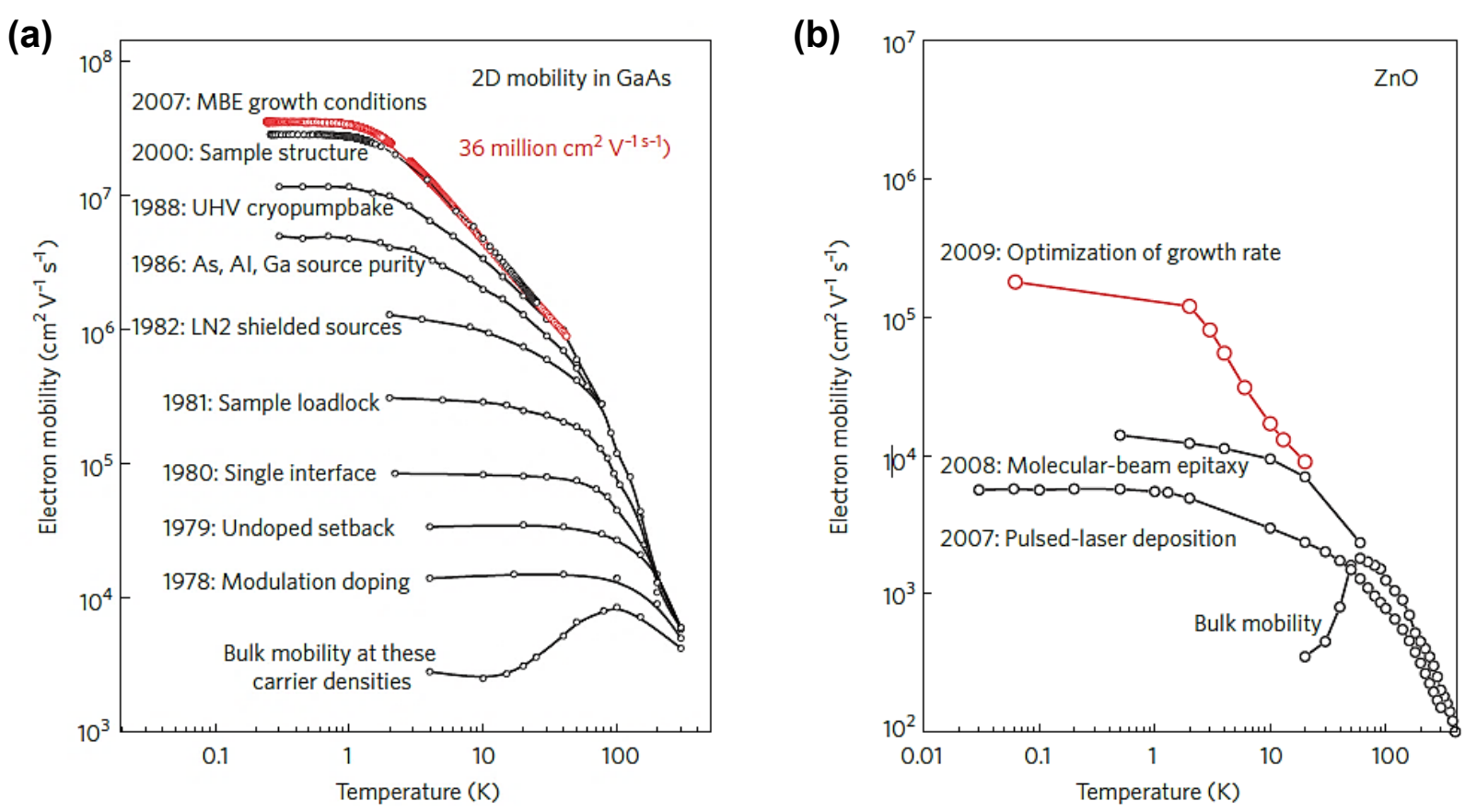

Figure 4. (a) Electron mobilities reported by Bell laboratories in GaAs. Labels are as follows: MBE: molecular-beam epitaxy, UHV: ultra-high vacuum, LN2: liquid nitrogen, "undoped setback": an undoped layer prior to the modulation doping to further separate the ionized impurities from the 2-dimensional electron gas. (b) Peak reported electron mobility as of 2010 in $\mathrm{ZnO}$-based heterostructures as a function of temperature. These figures have now been improved upon, and at the time of press the highest reported mobility in such a structure is in excess of 700,000 $\mathrm{cm}^{2} \mathrm{~V}^{-1} \mathrm{~s}^{-1}$. Adapted by permission from Macmillan Publishers Ltd: Nature Materials (Ref. [5]), copyright (C) 2010. 
(a)
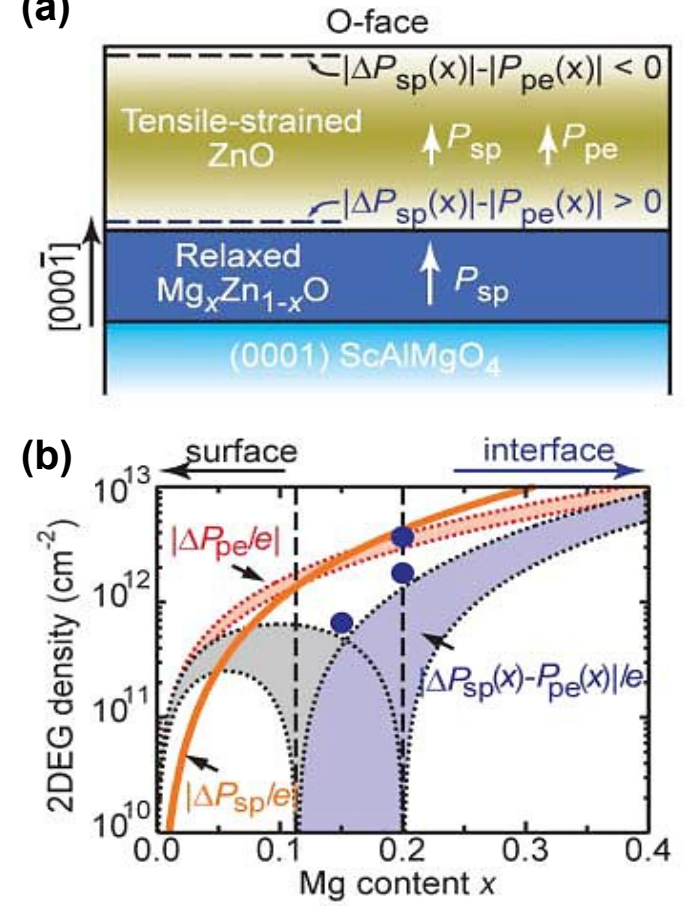

(c)

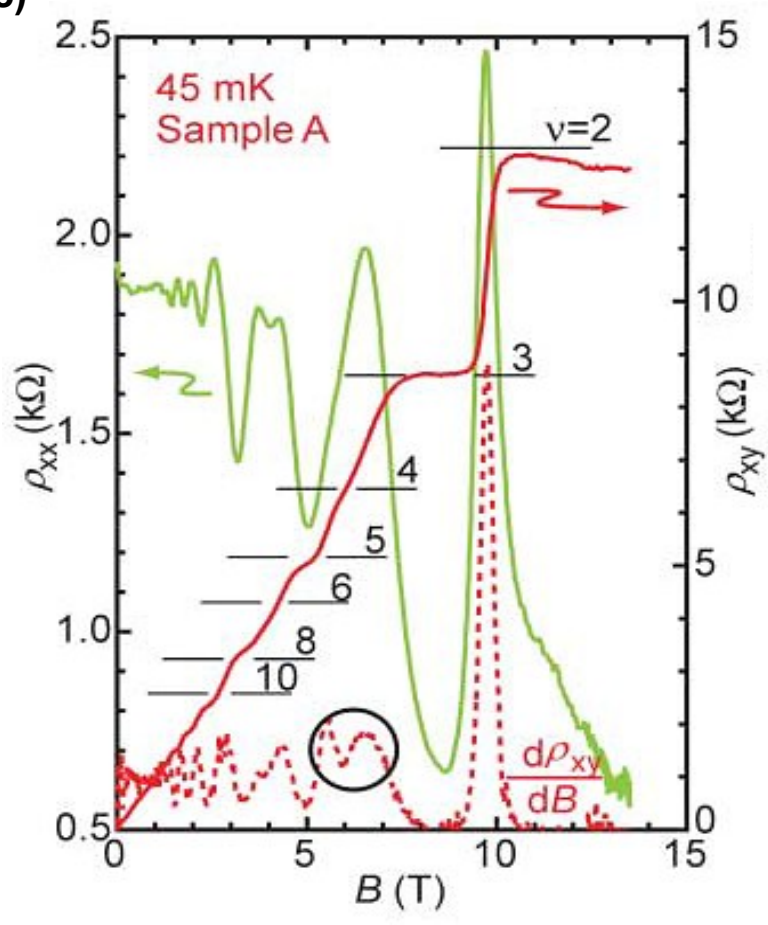

Figure 5. (a) Schematic representation of $\mathrm{ZnO} / \mathrm{Mg}_{\mathrm{x}} \mathrm{Zn}_{1-\mathrm{x}} \mathrm{O}$ heterostructure grown on $\mathrm{ScAlMgO}_{4}$ substrates via molecular beam epitaxy. A strain-induced change in polarisation causes accumulation layers to form at the regions indicated by the dashed lines. $\mathrm{P}_{\mathrm{sp}}(\mathrm{x})$ is the spontaneous polarization in the unstrained $\mathrm{Mg}_{\mathrm{x}} \mathrm{Zn}_{1-\mathrm{x}} \mathrm{O}$ layer and $\mathrm{P}_{\mathrm{sp}}(\mathrm{x})$ is the piezoelectric polarization in the strained $\mathrm{ZnO}$ layer. (b) Calculated (shaded regions) and measured (blue dots) electron density as a function of $\mathrm{Mg}$ content (x) at the interface. (c) Longitudinal resistivity $\rho_{\mathrm{xx}}$, Hall resistivity $\rho_{\mathrm{xy}}$, and differential Hall resistivity $\mathrm{d} \rho_{\mathrm{xy}} / \mathrm{dB}$ of $\mathrm{ZnO} / \mathrm{Mg}_{\mathrm{x}} \mathrm{Zn}_{1-\mathrm{x}} \mathrm{O}$ heterostructure as a function of magnetic field. Integers on the horizontal tick marks are the Landau level filling factors defined as $n=h /\left(\rho_{x y} e^{2}\right)$. Reproduced from Ref. [17] with permission from Science, copyright (C) 2007. 

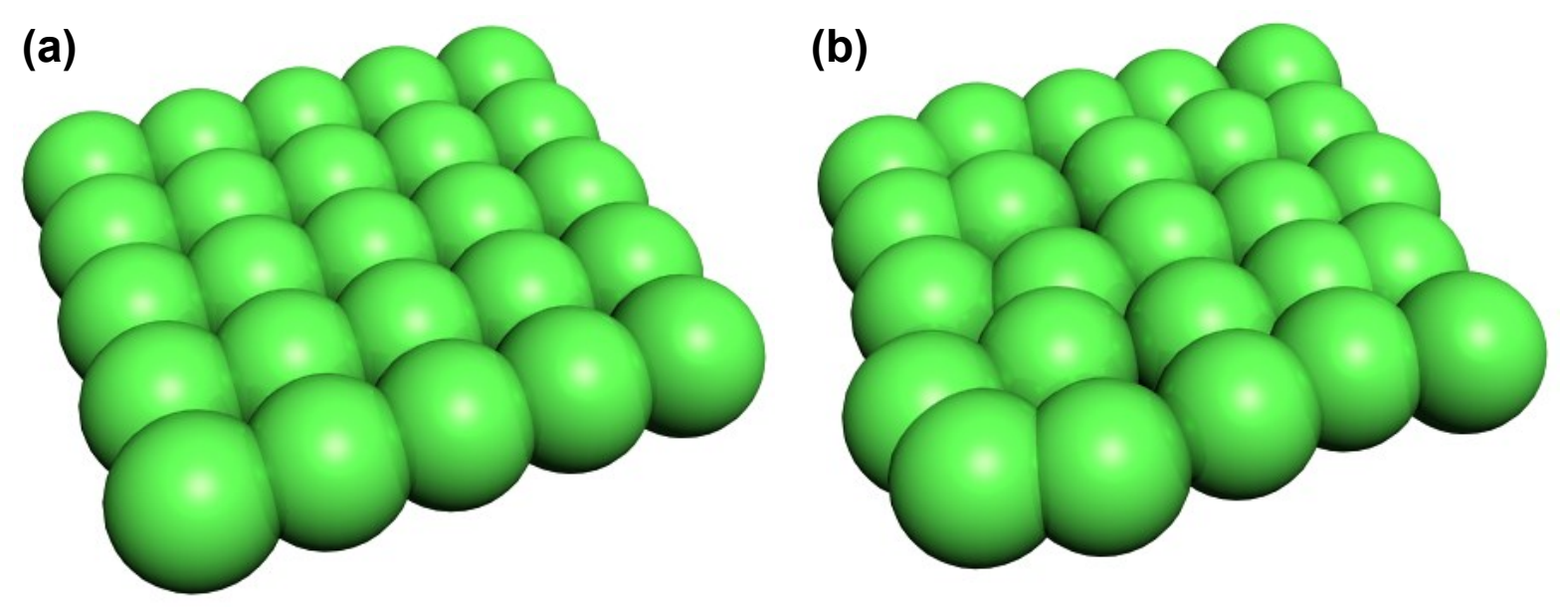

Figure 6. Schematic representation of orbitals associated with electron transport in (a) ordered and (b) disordered semiconductor metal oxides. The spherical nature of the ns-type orbitals is believed to make the wavefunction overlap and transport properties of the system less dependent on its morphology than a $s p$-hybridized system such as silicon or organic semiconductors. $^{[53]}$ 


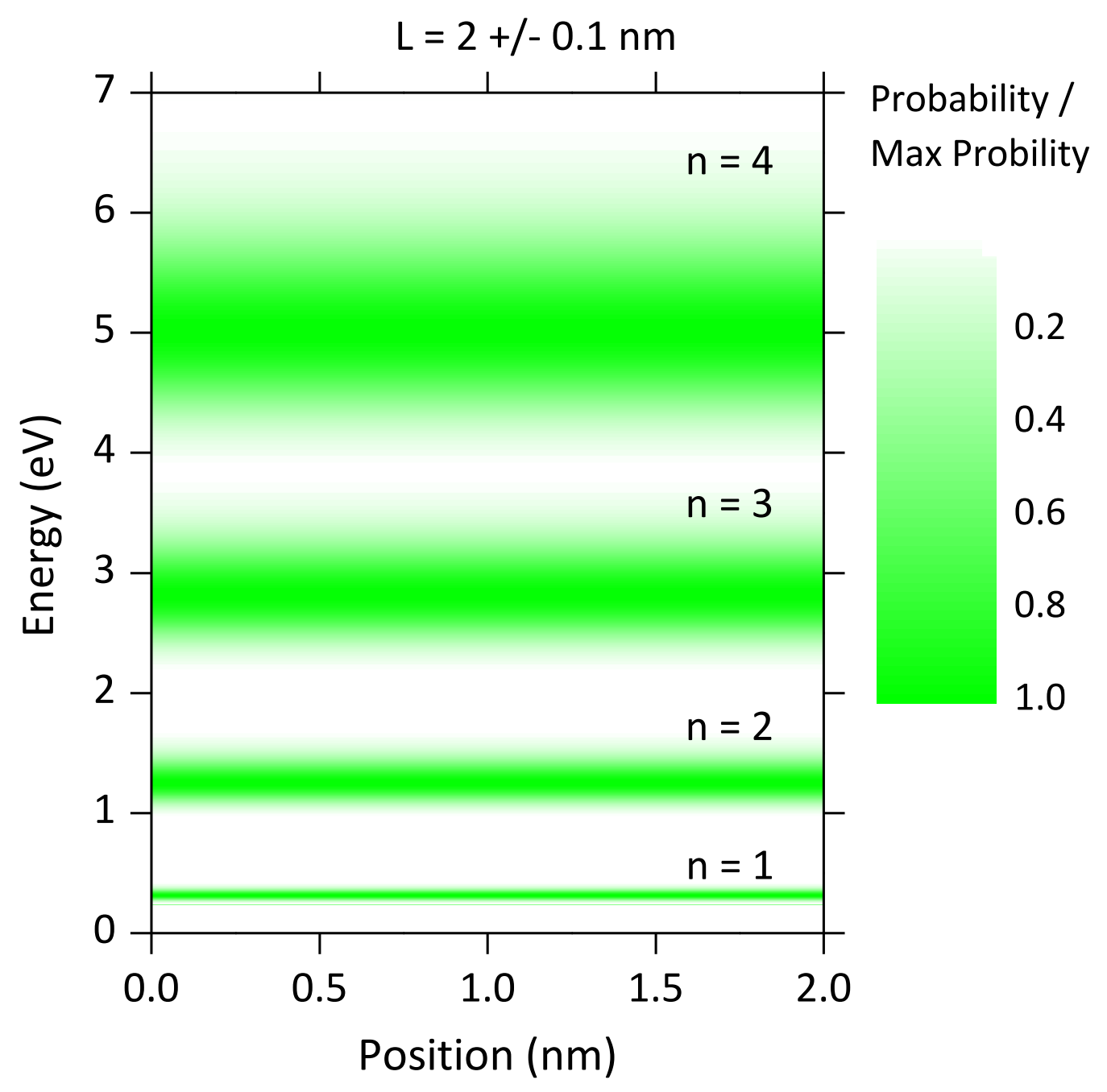

Figure 7. Illustrative example of probability distribution of energies available to an electron in infinite quantum well with a finite roughness. Energies represented by a dark green color are those which are most probable for a certain quantum number n, whilst white represents energies with a probability zero. Energies have been calculated for a quantum well with a mean width of $2 \mathrm{~nm}$ and a width standard-deviation of $1 \AA$. Reproduced from Ref. [74] with permission from John Wiley and Sons, copyright (C) 2015. 
(a)

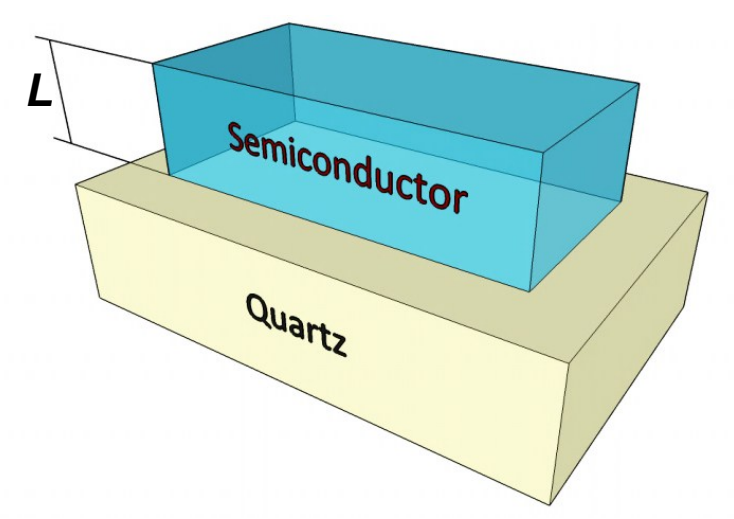

(b)

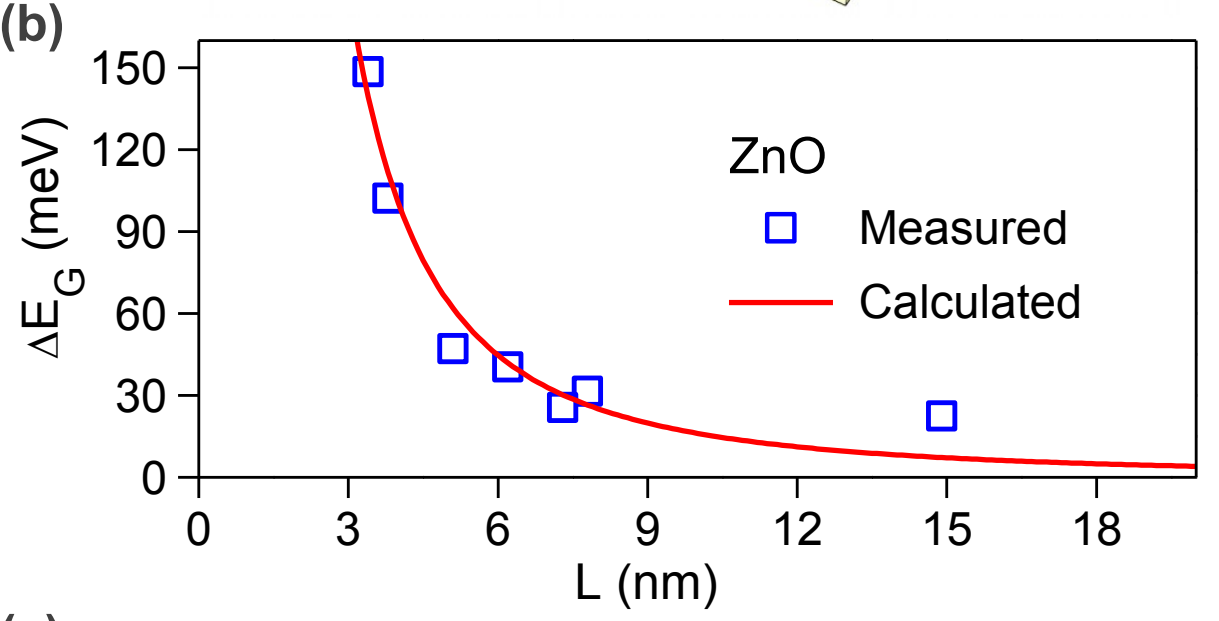

(c)

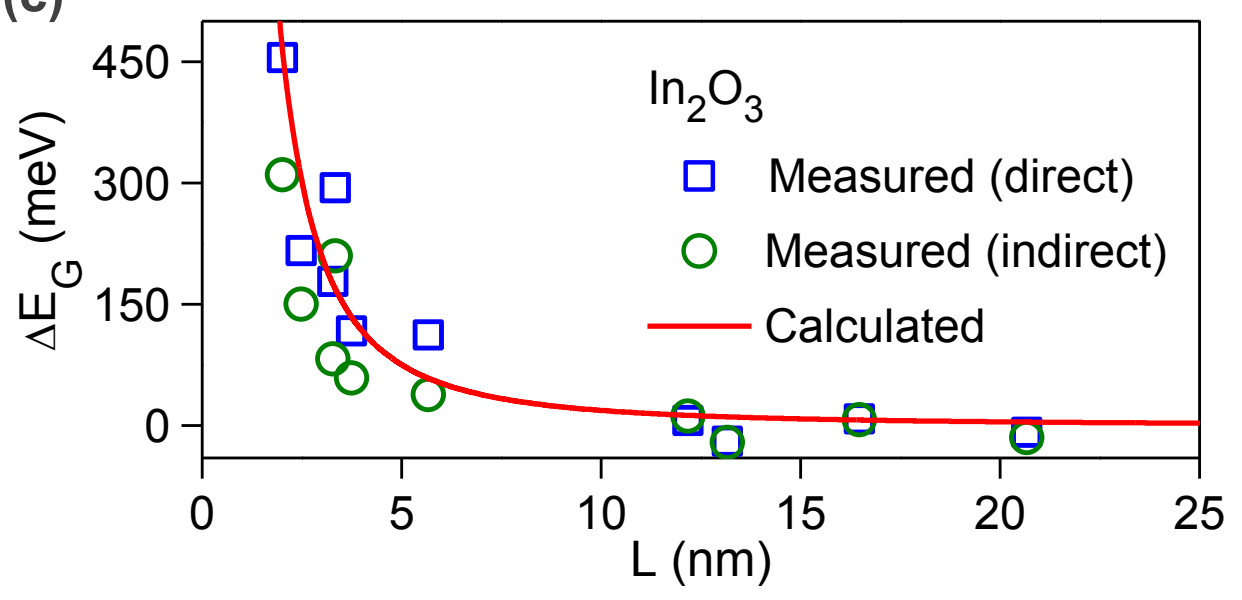

Figure 8. (a) Schematic representation of solution-processed metal oxide semiconductor deposited onto quartz substrate with a mean thickness of $L$. (b) Open squares: Shift in optical band gap of several ultra-thin $\mathrm{ZnO}$ films deposited onto quartz as a function of mean film thickness $(L)$ with respect to bulk $\mathrm{ZnO}$. The optical band gap of all films was approximated using Tauc analysis and films with thicknesses in excess of $15 \mathrm{~nm}$ were considered to be representative of bulk $\mathrm{ZnO}$. (c) Open points: Shift in optical band gap of several ultra-thin 
$\mathrm{In}_{2} \mathrm{O}_{3}$ films deposited onto quartz as a function of mean film thickness $(L)$ with respect to bulk $\mathrm{In}_{2} \mathrm{O}_{3}$. The optical band gap of all films was approximated using Tauc analysis and films with thicknesses in excess of $20 \mathrm{~nm}$ were in this case considered to be representative of bulk $\operatorname{In}_{2} \mathrm{O}_{3}$. Due to debate in the literature on the nature of the band gap in $\operatorname{In}_{2} \mathrm{O}_{3}$ Tauc analysis was applied assuming both a direct (squares) and indirect (circles) band gap. The solid lines in (b) and (c) are the calculated change in optical band gap for $\mathrm{ZnO}$ and $\operatorname{In}_{2} \mathrm{O}_{3}$ respectivley, where the films are modelled as infinite potential wells. Reproduced from Ref. [78] under the Creative Commons Attribution License (CC BY) license, copyright C 2015. 
(a)

\begin{tabular}{|c|c|}
\hline \multirow[b]{2}{*}{ Heterojunction } & QSL-I \\
\hline & $\mathrm{ZnO}$ \\
\hline Oxide 1 & $\mathrm{Ga}_{2} \mathrm{O}_{3}$ \\
\hline Oxide 2 & $\ln _{2} \mathrm{O}_{3}$ \\
\hline \multirow[t]{3}{*}{ substrate } & substrate \\
\hline & $\ln _{2} \mathrm{O}_{3}$ \\
\hline & $\mathrm{Ga}_{2} \mathrm{O}_{3}$ \\
\hline $\ln _{2} \mathrm{O}_{3}$ & $\mathrm{ZnO}$ \\
\hline $\mathrm{ZnO}$ & $\mathrm{Ga}_{2} \mathrm{O}_{3}$ \\
\hline $\ln _{2} \mathrm{O}_{3}$ & $\ln _{2} \mathrm{O}_{3}$ \\
\hline substrate & substrate \\
\hline QSL-I & QSL-III \\
\hline
\end{tabular}

(c)

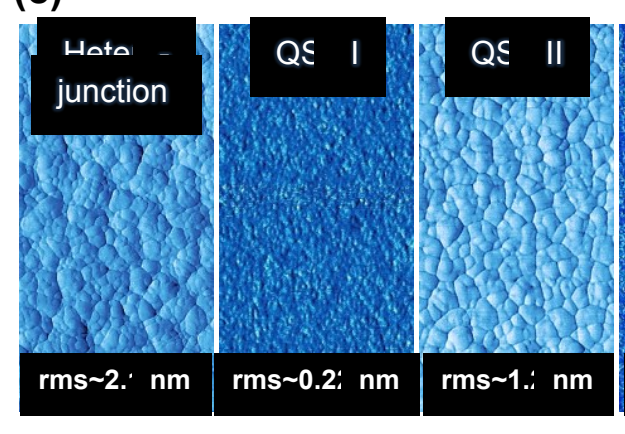

(b)

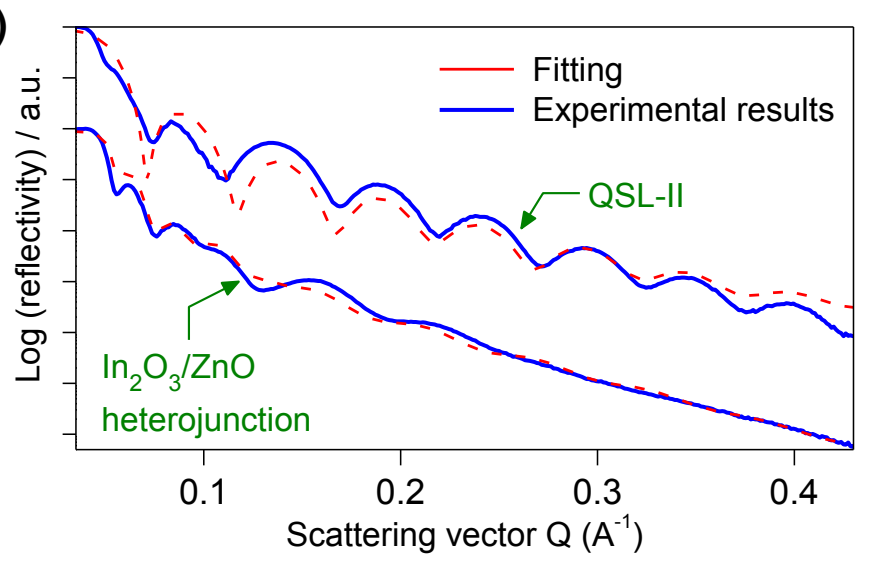

(d)

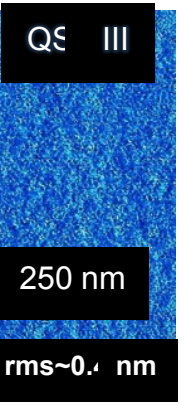

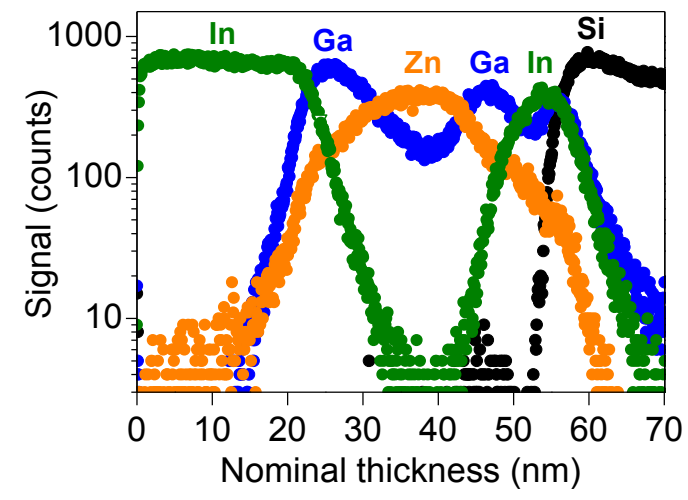

Figure 9. (a) Schematics representations of solution-prcoessed multilayer structures grown including heterojunctions $\left(\mathrm{In}_{2} \mathrm{O}_{3} / \mathrm{ZnO}, \mathrm{In}_{2} \mathrm{O}_{3} / \mathrm{Ga}_{2} \mathrm{O}_{3}, \mathrm{ZnO} / \mathrm{Ga}_{2} \mathrm{O}_{3}\right)$ and multilayer QSLs consisting of $\mathrm{In}_{2} \mathrm{O}_{3} / \mathrm{ZnO} / \mathrm{In}_{2} \mathrm{O}_{3} \quad(\mathrm{QSL}-\mathrm{I}), \quad \mathrm{In}_{2} \mathrm{O}_{3} / \mathrm{Ga}_{2} \mathrm{O}_{3} / \mathrm{ZnO} \quad$ (QSL-II) and $\mathrm{In}_{2} \mathrm{O}_{3} / \mathrm{Ga}_{2} \mathrm{O}_{3} / \mathrm{ZnO} / \mathrm{Ga}_{2} \mathrm{O}_{3} / \mathrm{In}_{2} \mathrm{O}_{3}$ (QSL-III). (b) Measured (solid lines) and calculated (dashed lines) X-ray reflectometry spectra of the $\operatorname{In}_{2} \mathrm{O}_{3} / \mathrm{ZnO}$ and QSL-II layered structures. (c) Atomic force microscope surface phase images of the heterojunction, QSL-I, QSL-II and QSL-III structures. (d) TOF-SIMS analysis for a QSL-III grown on $\mathrm{Si}^{++} / \mathrm{SiO}_{2}$ substrate. A thicker top layer of $\operatorname{In}_{2} \mathrm{O}_{3}(\sim 25 \mathrm{~nm})$ was used in order to stabilize the ion beam during measurement. Reproduced from Ref. [78] under the Creative Commons Attribution License (CC BY) license, copyright (C) 2015 . 
(a)

HJ

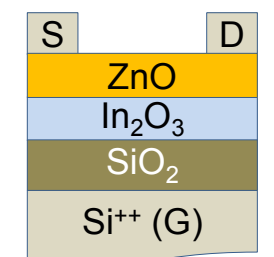

QSL-I

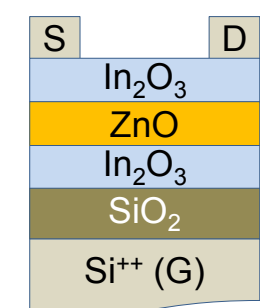

QSL-II

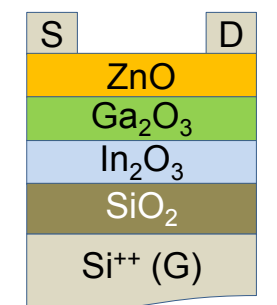

QSL-III

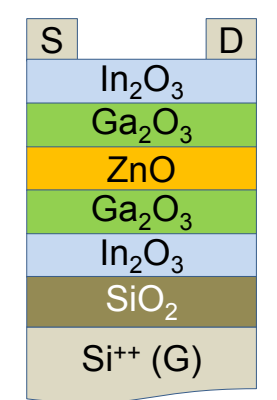

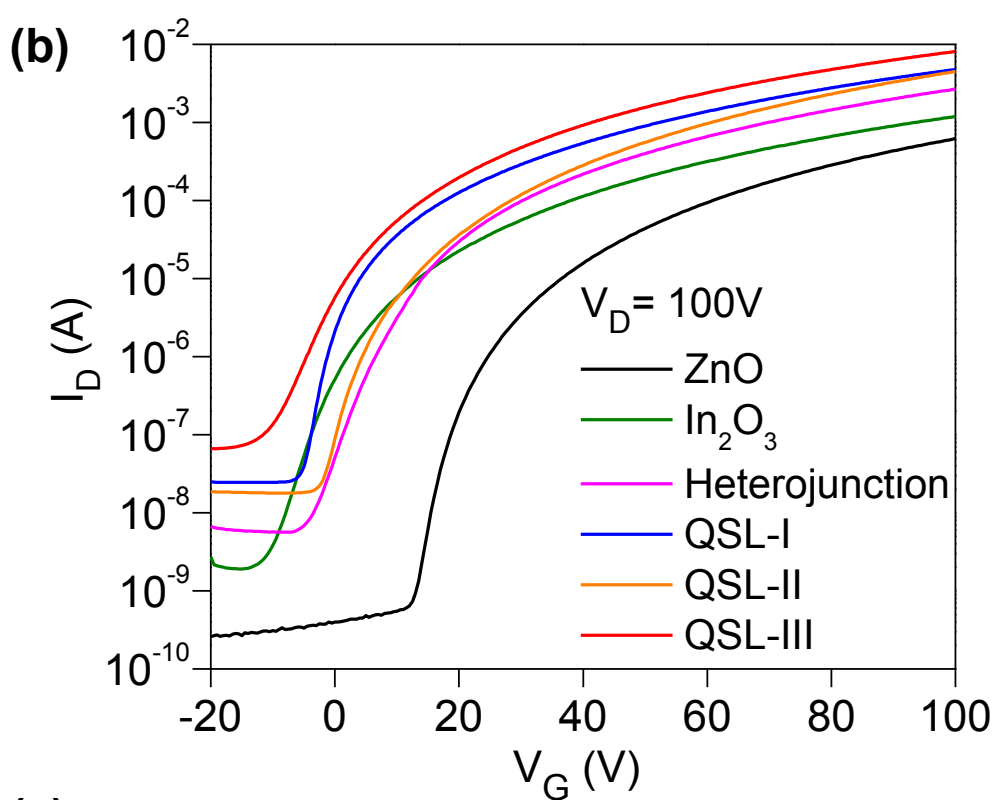

(c)

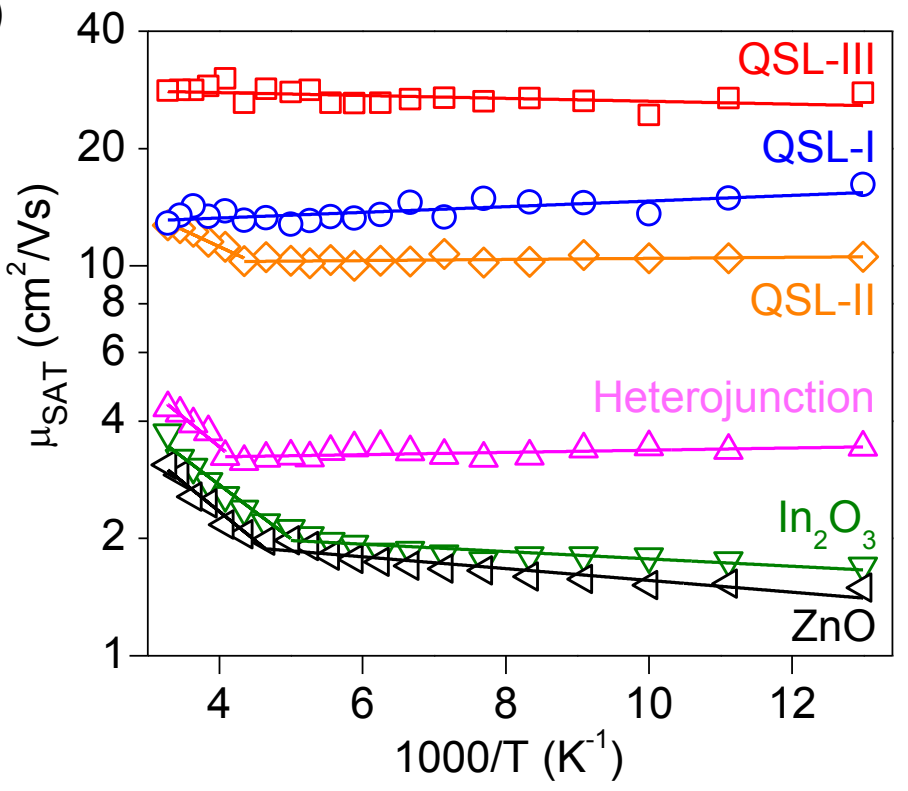

Figure 10. (a) Schematic representation of solution-processed single-layer and multilayer [i.e. quasi-superlattice (QSL)] oxide bottom-gate, top-contact thin-film transistors developed using $\mathrm{Si}^{++}$and $\mathrm{SiO}_{2}(400 \mathrm{~nm})$ as the gate and the gate dielectric, respectively. (b) Example transfer characteristics of transistors with different oxide-based device architecture. (c) Arrhenius plots of the temperature dependence of electron mobility $\left(\mu_{\mathrm{FE}}\right)$ for $\mathrm{ZnO}, \mathrm{In}_{2} \mathrm{O}_{3}$, heterojunction, QSL-I, QSL-II and QSL-III based transistors measured in saturation at $\mathrm{V}_{\mathrm{G}}=80 \mathrm{~V}$ and $\mathrm{V}_{\mathrm{D}}=$ 100 V. Reproduced from Ref. [78] under the Creative Commons Attribution License (CC BY) license, copyright $\mathbb{C} 2015$. 
a

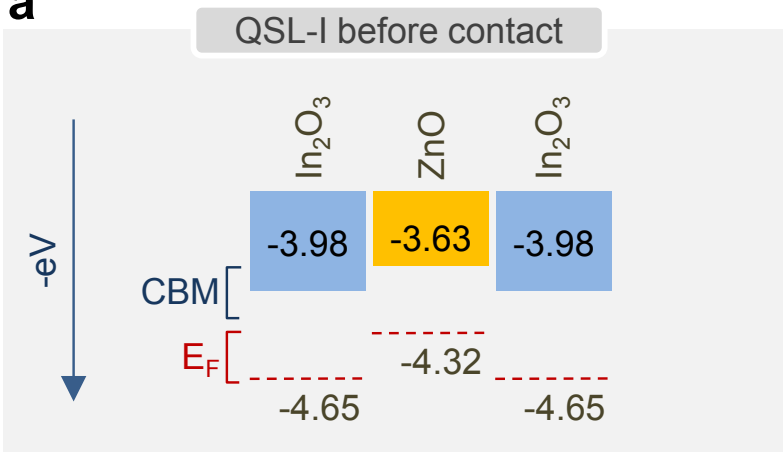

C

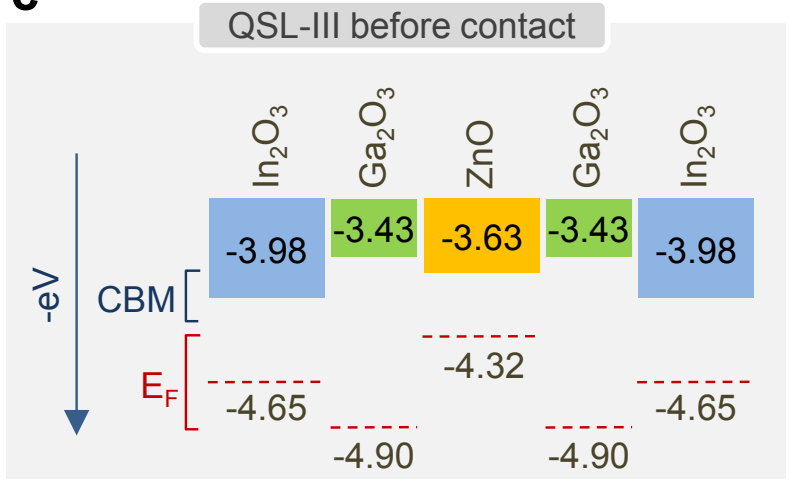

b

QSL-I after contact

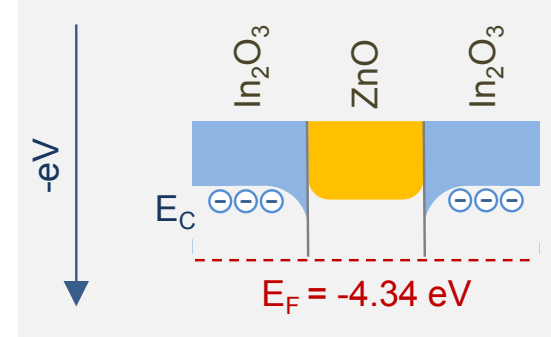

d

QSL-III after contact

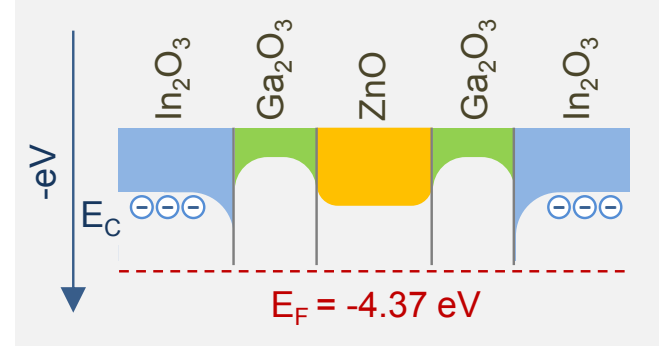

Figure 11. (a) Energy band diagrams for the oxides used in quasi-superlattice 1 (QSL-I) and quasi-superlattice 3 (QSL-III) transistors before $(\mathrm{a}, \mathrm{c})$ and after $(\mathrm{b}, \mathrm{d})$ physical contact. It has been argued that due to the differences in their Fermi energy $\left(\mathrm{E}_{\mathrm{F}}\right)$ and the low-dimensionality of the individual layers, electron transfer from $\mathrm{ZnO}$ to $\mathrm{In}_{2} \mathrm{O}_{3}$ occurs upon contact leading to the formation of a 2DEG-like system. Reproduced from Ref. [78] under the Creative Commons Attribution License (CC BY) license, copyright (C) 2015. 